\title{
Do Equity Markets Favor Credit Market News Over Options Market News? ${ }^{1}$
}

\author{
Antje Berndt and Anastasiya Ostrovnaya ${ }^{2}$
}

\section{Current version: August 2008}

\begin{abstract}
Both credit default swap (CDS) and options markets often experience abnormal swings prior to the announcement of negative credit news. With the exclusion of negative earnings announcements, we find that options prices reveal information about such forthcoming adverse events at least as early as do credit spreads. Prior to negative credit news being publicly disclosed, we find that the equity market does not respond to abnormal movement in options prices unless that information has also manifested itself in the CDS market. A potential explanation is that options are more likely to trade on unsubstantiated rumors than are default swaps.
\end{abstract}

JEL Classifications: G12; G13; G14; D8

Keywords: Credit and equity derivatives; Lead-lag analysis; Accounting scandals; Negative Earnings; Leveraged Buyouts

\footnotetext{
${ }^{1}$ We thank Markit for providing us with data on credit default swap rates. We are grateful to Rick Green, Jens Hilscher, Timothy Johnson, Bryan Routledge, Fallaw Sowell, Eric Stone, Fabio Trojani, Gaiyan Zhang, and Stanley Zin for extended discussions. We would also like to thank participants at the Second Conference on Advances in Hedge Fund Strategies, the 2008 AFA Annual Meetings and the 2008 NASM of the Econometric Society for useful comments. An earlier version of this paper circulated as a working paper under the title "Information Flow between Credit Default Swap, Options and Equity Markets."

${ }^{2}$ Berndt is with the Tepper School of Business, Carnegie Mellon University, and Ostrovnaya is at Deutsche Bank, London. Corresponding author: Antje Berndt (Address: 5000 Forbes Avenue, Tepper School of Business, Carnegie Mellon University, Pittsburgh, PA 15213; Phone: 412-268-1871; Fax: 412-268-7064; Email: aberndt@andrew.cmu.edu).
} 


\section{Introduction}

In the recent past, there have been dramatic spikes in the prices of credit default swaps (CDS), over-the-counter securities that provide default insurance on debt. These contracts are popular among commercial banks, hedge funds, and other big investors. In some prominent cases, including deals involving hospital operator HCA Inc. and energy company Anadarko Petroleum, prices of the default swaps climbed in the days before news of major acquisitions became public (Scannell and Ng, 2006). This suggests that some traders might have acted on inside information, especially since CDS contracts are negotiated privately and over the phone, not on a regulated exchange.

Acharya and Johnson (2007a) — in an important contribution to the literatureuse news reflected in the stock market as a benchmark for public information and identify a significant incremental revelation of information in the CDS market for adverse credit news and for firms that subsequently experience adverse shocks. The degree of advance information increases with the number of banks that have lending or monitoring relationships with the given firm. The authors argue that these findings are consistent with the use of nonpublic information by informed banks.

This paper extends the analysis in Acharya and Johnson (2007a) by treating information reflected in the stock market or the options market as the benchmark against which to measure incremental information revelation in CDS markets. There is strong evidence that options-market news contains information about future stock prices. For example, Easley, O'Hara, and Srinivas (1998) and Pan and Poteshman (2006) find that signed options trading volume can help forecast future stock returns. Cao, Chen, and Griffin (2005), among others, document abnormal trading volume in options markets prior to take-over announcements.

Anecdotal evidence of both credit spreads and options prices revealing information prior to the stock market can be found in the case of Harrah's Entertainment's recent leveraged buyout (LBO) announcement. On October 2, 2006 the world's biggest gambling operator received a $\$ 15$ billion buyout offer from two private equity firms. 
The Wall Street Journal (WSJ) article "Trading in Harrah's Contracts Surges Before LBO Disclosure" from October 4, 2006 describes how both options and derivatives markets experienced abnormal swings two days prior to the announcement, whereas the stock market was much slower to respond.

We present more extensive empirical evidence that both CDS and options markets often experience abnormal upward swings prior to the announcement of negative credit news. ${ }^{1}$ Acharya and Johnson (2007a) identify such adverse events as times when credit spreads widen by 50 basis points over a one-day period. We deviate from using an absolute threshold for a number of reasons: First, a 50-basis-point spread increase is more common and often represents a less dramatic event for low-creditquality firms than for investment-grade firms. Second, the increase might stem from a sudden industry- or market-wide surge in spreads rather than from a firm-specific event. Although a conditional flow of information from the CDS market is of interest either way, the observed lead-lag relationships are potentially quite different for these two scenarios.

Third, credit spreads may widen due to or in anticipation of value-deteriorating news or debt-deteriorating news. News releases that represent an adverse shock to both equity and bond holders of a company are labeled value-deteriorating. Examples include announcements of accounting irregularities, fraud, lower-than-expected earnings and lowering of forecasts. Debt-deteriorating news releases, on the other hand, are announcements that represent an adverse shock to the creditors of a firm but that leave equity holders equally or even better off. In this sense, they are likely to lead to a widening of credit spreads while stock prices stay flat or even increase. An example are announcements that the firm is the target of a LBO deal.

Recognizing that news that widens credit spreads can be classified into these two categories will help detect not just a conditional flow of information from the CDS and the options markets to the equity market, but also in correctly measuring the sign and magnitude of such incremental spillover effects. For example, Figs. 1 and 2

\footnotetext{
${ }^{1}$ We focus exclusively on negative types of events because Acharya and Johnson (2007a) find that there are no significant flows from CDS to equity markets for positive information events.
} 
show the daily returns on stocks, options, and default swaps for a debt-deteriorating news event (HCA Inc.) and for a value-deteriorating announcement (Delphi Corp.), respectively. Hospital operator HCA announced that it had agreed to a $\$ 21$ billion buyout for a $6.5 \%$ premium on July 24, 2006. Fig. 1 shows that CDS rates rose in the week leading up to the announcement. Put-option-implied volatilities as well as stock prices dramatically increased two days prior to the news release, with HCA's shares climbing to a high on the day of the announcement and trading fairly flat at that level the week after. For HCA, implied volatilities dramatically decrease after the initial upward jump, to a level significantly lower than before the information was revealed. Auto-parts supplier Delphi, on the other hand, disclosed further accounting problems on March 7, 2005. Here, the picture looks somewhat reversed. All three markets show a strong adjustment four days prior to the announcement, with credit spreads and put-implied volatilities dramatically increasing, and with significant negative returns on stocks.

To address the first issue, we replace the 50-basis-point rule with an alternative definition of adverse credit-market events. The second and third issues are dealt with by studying the revelation of information in credit, options, and equity markets around adverse firm-specific announcements. To identify firm-specific news releases, we run a full-text search of all WSJ articles since 2002, obtaining a total of more than 21,750 articles related to firms in our sample. Among those we then search for announcements that signal a potentially adverse effect on the value of the company's debt. In particular, we collect announcements related to accounting irregularities and fraud (Type A), lower-than-expected earnings or lowered forecasts (Type E), the firm selling a unit or assets (Type S), the firm buying another company or unit (Type B), and the firm being a target of a leveraged buyout (Type L).

The first contribution of our paper is a rigorous investigation of whether or to what extent the credit market acquires information prior to the options market, or vice versa. Our results indicate that $(i)$ investors absorb information revealed in the CDS market into prices of equity options within a few days and vice versa, (ii) the 
incremental conditional information flow from CDS to options markets is significant for high-yield and for highly volatile firms, and (iii) there is a strong conditional spillover from the options market to the CDS market during the week around a dramatic increase in implied volatility, as well as for highly volatile firms.

Running the horse race between the credit market and the options market shows that in general there is no clear winner: With the exclusion of negative earnings announcements, we find that options prices reveal information about forthcoming negative credit news at least as early as do credit spreads. Prior to certain adverse credit-market events, notably the disclosure of accounting scandals, we even find that the incremental information revelation in the options market relative to the CDS market is significant.

Our second contribution is to quantify the joint contribution of the CDS market and the options market to price discovery relative to the stock market. We find that (i) the unconditional flow of information from the credit and the options market to the equity market is negative but very small, (ii) the incremental spillover effect from CDS to equity markets is more negative for highly volatile and for large firms, (iii) conditional spillover effects from options to equity markets are stronger for highly volatile firms and for smaller firms, (iv) there is a strong conditional spillover from CDS to equity markets for announcements of Type E, S and L, even after controlling for the news revealed in options prices, and $(v)$ with the exception of Type L news, we do not detect any incremental spillover effects from options to equity markets for announcement types A, E, S or B. And even for leveraged buyout announcements, the equity market first reacts to news in credit spreads and only afterwards to movement in options prices.

For all five types of announcements A, E, S, B and L we find that the equity market does not respond to abnormal movement in options prices in the period prior to the news being publicly disclosed unless that information has also manifested itself in the CDS market. A potential explanation is that options are more likely to trade on unsubstantiated rumors than default swaps are. We substantiate this conjecture 
by analyzing the differences in CDS-market and options-market participants, and by offering empirical evidence that dramatic upward jumps in implied volatilities are revised more frequently and sooner than are dramatic upward jumps in CDS.

News unrelated to negative credit news may set off so-called "piggyback" buying from options traders hoping to catch a lucky break. Berman and Ng (2006) argue that in many of these instances, such as for Starwood Hotels \& Resorts Worldwide Inc., the trading stir ends in a whimper and no deal ever materializes. As a result, if there is a sudden upward jump in implied volatility that is not accompanied by a reaction in credit spreads that day or shortly afterwards, equity-market participants may be more likely to believe that the change in option prices was due to unsubstantiated rumors rather than new information.

The third contribution of our paper is to propose a framework for the arrival and transmission of information in CDS, options and equity markets. The model allows for credit-market and options-market participants to have access to insider information about forthcoming adverse events, and the latter may also trade on unsubstantiated rumors. The specification of stock returns captures the notion that investors in equity markets are strongly adverse to trading on rumors. Stock prices will adopt to new information only when it is publicly announced, or if it is revealed through a dramatic surge in credit spreads prior to the news release. A simulation study shows that the proposed model, although very simple, is rich enough to capture the essence of our empirical findings.

\section{Related Literature}

The existing literature on the information flow between the CDS, options, and equity markets focuses either on $(i)$ the CDS, bond, and equity markets only; (ii) the options and equity markets only; or (iii) the explanatory power of implied volatilities and option-implied jump risk premia for credit spreads. All three strands of the literature are briefly reviewed below. Two exceptions are the concurrent works by Cao, Yu, and Zhong (2007) and by Buraschi, Trojani, and Vedolin (2007). The former paper examines unconditional lead-lag relationships between CDS, options and equity mar- 
kets for different groups of firms, whereas the latter shows that disagreement among investors consistently impacts credit spreads, stock returns, and the volatility smile of individual options.

Blanco, Brennan, and Marsh (2005) show that for a sample of high-grade credits there is a greater price discovery in the CDS market than in the bond market, although the reverse seems to occur as well. Norden and Weber (2007) look at the comovement of the CDS, bond, and stock markets and find that the stock market generally leads the CDS and bond markets, that the CDS market is more responsive to the stock market than to the bond market, and that the CDS market plays a more important role in price discovery than the bond market does. Longstaff, Mithal, and Neis (2005) examine the weekly lead-lag relationships between CDS spread changes, corporate bond spreads, and stock returns for U.S. firms using a VAR framework. Their results show that the stock and CDS markets lead the corporate bond market. Somewhat in contrast to Acharya and Johnson (2007a), the authors argue that there is no clear leader between the stock market and the CDS market.

Focusing on lead-lag relationships between equity and equity options, Chakravarty, Gulen, and Mayhew (2004) argue that option trading contributes to price discovery in the underlying stock market. Informed traders trade in both stocks and options, suggesting an important informational role for options. Easley, O'Hara, and Srinivas (1998) and Pan and Poteshman (2006) find that signed trading volume in the options markets can help forecast future stock returns. Cao, Chen, and Griffin (2005), among others, document abnormal trading volume in the options market prior to take-over announcements. Our paper contributes to this strand of the literature by investigating price discovery in the options market, while controlling for the information content of the CDS market.

With regard to the explanatory power of options-market information for credit spreads, Cao, Yu, and Zhong (2007) find that at the firm level, contemporaneous option-implied volatilities dominate historical volatilities in explaining CDS spreads. (Cremers, Driessen, Maenhout, and Weinbaum (2005) and Hilscher (2007) have simi- 
lar results for corporate bond yield spreads.) To accommodate the nonlinear relation between CDS spreads and implied volatility, Cao, Yu, and Zhong (2007) estimate a structural credit risk model called "CreditGrades." In contrast, Cremers, Driessen, Maenhout, and Weinbaum (2005) and Zhang, Zhu, and Zhu (2005) explain default swap spreads with option-implied jump risk premia.

Finally, there are a two event studies that relate to our work. Norden and Weber (2004) analyze credit and equity markets around announcements of rating changes, and, in a recent paper, Acharya and Johnson (2007b) focus on private equity buyouts and investigate whether the number of financing participants is related to the likelihood of insider trading prior to the bid announcement.

The remainder of this paper is structured as follows. Section 2 describes our data, discusses the econometric techniques employed in the paper, and provides details on the firm-specific announcements studied. As a preliminary analysis, Section 3 investigates the cross-correlation structure between CDS, options, and equity markets. Section 4 describes our findings regarding the flow of information from the CDS market to the options market and vice versa, and Section 5 extends the analysis to include the equity market. In Section 6, we propose a model of information arrival and transmission for credit, options and equity markets that is rich enough to capture the essence of our empirical findings. Finally, Section 7 discusses our conjecture that the options market trades on unsubstantiated rumors more frequently than does the default swap market, and then concludes.

\section{Data and Definitions}

\subsection{Data}

Our analysis is based on daily CDS, options, and equity data for 144 U.S. firms from nine industries: basic materials (10 firms), consumer goods (24), consumer services (14), healthcare (20), industrials (18), oil and gas (21), technology (10), telecommunications (12), and utilities (15). It covers the period from January 1, 
2002 to November 8, 2006. Summary statistics are provided in Table 1. For each sector, we report the number of firms, the average number of daily default swap observations per firm, the median CDS rate, and the distribution of the median S\&P long-term issuer rating for the firms in that sector. Table 1 indicates that the range of credit scores is concentrated around medium credit quality, with the majority of the firms having a $\mathrm{BBB}$ rating.

We now describe the data sources for the CDS, options, and equity markets in turn. A CDS is an over-the-counter derivative security that provides bond insurance. Fueled by participation from commercial banks, hedge funds, and insurance companies, CDS markets have grown exponentially over the past 10 years, reaching an outstanding notional value of more than $\$ 34.4$ trillion dollars in 2006 (International Swaps and Derivatives Association, 2007). The buyer of protection in a CDS contract pays a quarterly insurance premium until the expiration of the contract or until default by the reference entity, whichever occurs first. In return, the seller of protection pays to the buyer of protection the difference between the face value and the market value of the referenced debt. This compensation can be through physical delivery or cash delivery, with the former being more common.

CDS rates are quoted as annualized percentages of the notional value of the debt covered. Using an actual 360-day convention, the CDS rate is equal to four times the quarterly premium. Default swap spreads are provided by Markit and consist of daily five-year at-market CDS rates for senior-unsecured U.S.-dollar-denominated debt. Here, at-market denotes the premium rate at which the market value of the CDS contract at initiation is equal to zero. For our data, default events are triggered by bankruptcy, failure by the obligor to make payments on its debt, or a debt restructuring that is materially adverse to the interests of the creditors. For the latter, the modified ISDA contractual standards apply. In the case of physical settlement, modified debt restructuring restricts deliverable obligations to those that mature within 30 months of the CDS contract's maturity. For a debt restructuring event, this significantly decreases heterogeneity with regard to maturity, and hence market value, 
of the various deliverables.

Firm-by-firm pricing data for equity options are available from OptionMetrics. We download daily data on individual option-implied volatilities for standardized 60day at-the-money (ATM) put options. In OptionMetrics, implied volatilities (IV) of standardized options are computed by linearly interpolating the volatility surface to match the target expiration and the forward price, the underlying security's calculated price at expiration. A standardized option is only included if there are enough optionprice data on that date to accurately interpolate the required values. For each firm in our sample, we also download the daily total contract volume for calls and puts.

Daily closing prices for equity are downloaded from CRSP. To compute the distanceto-default measure in Section 2.2, we also access Compustat items 45 (Debt in Current Liabilities), 49 (Current Liabilities Total), and 51 (Long-Term Debt Total), as well as the numbers of shares outstanding from CRSP. Quarterly reported balance-sheet variables are interpolated linearly over the days in our sample.

\subsection{Econometric Analysis}

Price movements in equity, options, and credit markets are closely linked. To measure the flow of information originating from either the options market or the CDS market, we need to disentangle news arriving in one market from that present in other markets at the same time. After isolating innovations in the options and CDS markets, we discuss our choice of adverse options- and credit-market conditions under which we study the flow of information between the two derivatives markets and from the derivatives markets to the primary equity market. To better gauge the impact of adverse options- and credit-market events on the information flow, we identify events associated with either value- or debt-deteriorating news and replace options- and credit-condition dummies with announcement dummies for specific news categories. We now describe the econometric analysis involved in each of these steps. 


\subsection{1. $C D S$ and IV Innovations}

Within the standard structural framework of corporate default introduced by Black and Scholes (1973) and Merton (1974), the relationship between percentage changes in credit spreads and equity returns is highly nonlinear. Fig. 3 shows the elasticity of credit spreads with respect to the value of equity as implied by the Black-ScholesMerton model. The top panel relates this elasticity to the inverse of the level of credit spreads, whereas the bottom panel shows the elasticity of credit spreads as a function of the firm's distance to default (DD). Credit spreads on the x-axis range from 10 to 2,000 basis points, covering the range of spreads observed in our data. Acharya and Johnson (2007a) show the portion of the plot in the top panel of Fig. 3 that relates to credit spreads between 200 and 1,000 basis points. Most of the liquidity in the CDS market, however, stems from investment-grade firms, many of which trade at spreads far below 200 basis points.

The DD is defined as the number of standard deviations of asset growth with respect to the risk-neutral measure by which assets exceed a standardized measure of liabilities. In the Black-Scholes-Merton framework, risk-neutral default probabilities are a direct function of DD. The latter covariate is constructed along the lines of Duffie, Saita, and Wang (2007) using CRSP equity data and Compustat book liabilities. For our CDS sample, more than $85 \%$ of the quotes are below 200 basis points. Moreover, $90 \%$ of the default swap rates fall between 16 and 422 basis points, with a median spread of 51 basis points. For the model underlying Fig. 3 and an assumed asset volatility of $25 \%$, credit spreads of $16,51,200$, and 420 basis points compare to a DD of $2.41,1.96,1.31$, and 0.88 , respectively. A comparison of the two panels in Fig. 3 suggests that, for the range of credit spreads in our sample, the relation between spread elasticity and DD is close to affine, more so than that between spread elasticity and the inverse level of credit spreads.

To identify information arriving in the CDS markets that has not yet been revealed in the equity or options markets, we therefore regress percentage changes in CDS (CDSrtn) on contemporaneous and past stock returns (STKrtn), the product of those 
with DD, on percentage changes in implied volatilities (IVrtn), and on the past five lags of percentage changes in credit spreads. To account for the possibility that the elasticity of credit spreads with respect to the level of implied volatilities may be different for low-credit-quality firms from those for high-credit-quality firms, we also include interactions of percentage changes in individual implied volatilities (both contemporaneous and lagged) with the DD measure. For each firm $i$, we estimate the model

$$
\begin{aligned}
\operatorname{CDSrtn}_{t}^{i}=\alpha^{i} & +\sum_{k=0}^{5}\left[\beta_{k}^{i}+\gamma_{k}^{i} D D_{t}^{i}\right] \operatorname{STKrtn}_{t-k}^{i} \\
& +\sum_{k=0}^{5}\left[\delta_{k}^{i}+\zeta_{k}^{i} D D_{t}^{i}\right] \operatorname{IVrtn}_{t-k}^{i}+\sum_{k=1}^{5} \theta_{k}^{i} \operatorname{CDSrtn}_{t-k}^{i} \\
& +\operatorname{CDSinnov}_{\boldsymbol{e}, \boldsymbol{o}}^{i}(t) .
\end{aligned}
$$

We refer to the residuals CDSinnov $v_{e, o}^{i}(t)$ as innovations in the CDS market relative to the equity and options markets. Similarly, we use (1) to estimate innovations in the CDS market relative to the equity market, $\operatorname{CDSinnov}_{e}^{i}(t)$, and innovations in the CDS market relative to the options market, $C D \operatorname{Sinnov}_{o}^{i}(t)$, after setting $\delta_{t-k}^{i}=\zeta_{t-k}^{i}=0$ and $\beta_{t-k}^{i}=\gamma_{t-k}^{i}=0$, respectively.

Innovations in the options markets are estimated in a similar fashion. For each firm, we regress percentage changes in IV on contemporaneous and past stock returns, the product of those with $\mathrm{DD}$, on percentage changes in CDS rates, the product of those with DD, and on the past five lags of percentage changes in implied volatilities. The model is specified as

$$
\begin{aligned}
\operatorname{IVrtn}_{t}^{i}=\alpha^{i} & +\sum_{k=0}^{5}\left[\beta_{k}^{i}+\gamma_{k}^{i} D D_{t}^{i}\right] \operatorname{STKrtn}_{t-k}^{i} \\
& +\sum_{k=0}^{5}\left[\delta_{k}^{i}+\zeta_{k}^{i} D D_{t}^{i}\right] \operatorname{CDSrtn}_{t-k}^{i}+\sum_{k=1}^{5} \theta_{k}^{i} \operatorname{IVrtn}_{t-k}^{i} \\
& +\operatorname{IVinnov}_{\boldsymbol{e}, \boldsymbol{c}}^{i}(t),
\end{aligned}
$$

where the residuals IVinnov $v_{e, c}^{i}(t)$ are interpreted as innovations in the options markets 
relative to the equity and CDS markets. Finally, we also estimate innovations in the options markets relative to the equity market, IVinnov $v_{e}^{i}(t)$, and innovations in the options markets relative to the CDS market, $\operatorname{IVinnov}_{c}^{i}(t)$, by setting $\delta_{t-k}^{i}=\zeta_{t-k}^{i}=0$ and $\beta_{t-k}^{i}=\gamma_{t-k}^{i}=0$ in (2), respectively.

\subsubsection{Adverse Credit and Volatility Conditions}

In this section, we first describe the adverse credit conditions under which we study the flow of information from the CDS market to the options and equity markets. Afterwards, we introduce a set of volatility-condition variables that will be used to analyze the information flow originating from options markets.

For the purpose of this study, an adverse credit-market event is identified as a dramatic upward jump in CDS rates. For a given firm $i$, an upward jump in CDS rates occurs at time $t$ if

$$
\Delta C D S_{t}^{i}>\operatorname{avg}\left(\Delta C D S^{i}\right)+\Phi^{-1}(0.99) \operatorname{std}\left(\Delta C D S^{i}\right)
$$

where $\triangle C D S_{t}^{i}=C D S_{t}^{i}-C D S_{t-1}^{i}$ denotes the daily change in default swap rates and $\Phi$ is the standard normal cumulative distribution function. ${ }^{2}$ The functions avg $\left(\triangle C D S^{i}\right)$ and $\operatorname{std}\left(\triangle C D S^{i}\right)$ denote the sample mean and sample standard deviation of firm $i$ 's daily changes in default swap rates. When computing the sample movements, we use data spanning the whole period from January 2002 to November 2006 instead of an alternative specification that computes the sample averages in (3) using a moving window of, say, 30 or 60 days leading up to time $t$. One disadvantage of the latter specification is that following periods where spreads were relatively flat, any moderate move in rates translates into an adverse credit event for the firm even though the change in spreads most likely did not signal a drastic deterioration of its credit quality.

To study the conditional flow of information around adverse credit-market events, we introduce a set of credit-condition dummies to identify the three days prior to a

\footnotetext{
${ }^{2}$ We have repeated the empirical analysis in this paper for cutoff levels of 0.95 and 0.975 and confirmed that our findings are robust with regard to these choices.
} 
jump in CDS rates, the day of the event, and the three days immediately following it. For each firm $i$,

- $D_{\triangle C D S}^{\text {pre, } i}(s)$ equals one if (3) holds for $t \in\{s+1, s+2, s+3\}$ and zero otherwise,

- $D_{\triangle C D S}^{\text {at, } i}(s)$ equals one if (3) holds for $t=s$ and zero otherwise, and

- $D_{\triangle C D S}^{\text {post, } i}(s)$ equals one if (3) holds for $t \in\{s-1, s-2, s-3\}$ and zero otherwise.

The set of volatility-condition variables we use to analyze the flow of information from the options markets to the CDS and equity markets relies on a definition of IV jump events. For a given firm $i$, an upward jump in IV occurs at time $t$ if

$$
\Delta I V_{t}^{i}>\operatorname{avg}\left(\Delta I V^{i}\right)+\Phi^{-1}(0.99) \operatorname{std}\left(\Delta I V^{i}\right)
$$

where $\Delta I V_{t}^{i}=I V_{t}^{i}-I V_{t-1}^{i}$. Again, avg $\left(\Delta I V^{i}\right)$ and $\operatorname{std}\left(\Delta I V^{i}\right)$ denote the fullsample mean and standard deviation of firm $i$ 's daily changes in implied volatilities. For each firm $i$,

- $D_{\Delta I V}^{\text {pre, } i}(s)$ equals one if (4) holds for $t \in\{s+1, s+2, s+3\}$ and zero otherwise,

- $D_{\Delta I V}^{\text {at, } i}(s)$ equals one if (4) holds for $t=s$ and zero otherwise, and

- $D_{\Delta I V}^{\text {post, } i}(s)$ equals one if (4) holds for $t \in\{s-1, s-2, s-3\}$ and zero otherwise.

\subsubsection{Option Volume}

In addition to individual option-implied volatilities, we rely on options trading volume as an indicator for options market activity. ${ }^{3}$ Let $V \operatorname{lm} C_{t}^{i}$ and $V \operatorname{lm} P_{t}^{i}$ denote the total call and put contract volume for firm $i$ on date $t$, respectively. Similarly to (3) and (4), an upward jump in put option volume occurs for firm $i$ at time $t$ if

$$
\Delta V l m P_{t}^{i}>\operatorname{avg}\left(\Delta V l m P^{i}\right)+\Phi^{-1}(0.99) \operatorname{std}\left(\Delta V l m P^{i}\right)
$$

\footnotetext{
${ }^{3}$ Ideally, we would also like to explore the effect of signed options volume as in Easley, O'Hara, and Srinivas (1998) or of buyer-initiated options trades as in Pan and Poteshman (2006). Such data, however, is not available to us for the time period and firms in our study.
} 
where $\Delta V \operatorname{lm} P_{t}^{i}=V \operatorname{lm} P_{t}^{i}-V \operatorname{lm} P_{t-1}^{i}$. As before, $\operatorname{avg}\left(\Delta V \operatorname{lm} P^{i}\right)$ and $\operatorname{std}\left(\Delta V \operatorname{lm} P^{i}\right)$ denote the full-sample mean and standard deviation of firm $i$ 's daily changes in total put contract volume. For each firm $i$,

- $D_{\Delta V l m P}^{\mathrm{pre}, i}(s)$ equals one if (5) holds for $t \in\{s+1, s+2, s+3\}$ and zero otherwise,

- $D_{\Delta V l m P}^{\text {at, } i}(s)$ equals one if (5) holds for $t=s$ and zero otherwise, and

- $D_{\Delta V l m P}^{\text {post }, i}(s)$ equals one if (5) holds for $t \in\{s-1, s-2, s-3\}$ and zero otherwise.

Similar notation will be used for upward jumps in call option volume and the callvolume-condition dummy, after replacing $V \operatorname{lm} P$ with $V \operatorname{lm} C$.

\subsection{Announcements}

We start by compiling a complete list of announcements with regard to firms in our sample. For each firm we run a full-text search of all WSJ articles since January 2002 that contain one or more substrings related to the company's name (such as $A O L$ and Time Warner for Time Warner, Inc). This results in more than 21,750 newspaper articles. Among the articles for a given firm, we then search for news releases that signal a potentially adverse effect on the value of that firm's debt. This is facilitated by searching for keywords associated with four different types of announcements:

A: Accounting irregularities or fraud

Keywords: accounting, fraud, error, irregularit(ies), inquiry, restate, and delay.

E: Lower-than-expected earnings or forecast lowered Keywords: earning(s), forecast, loss, and profit

S: Firm is selling unit or assets

Keywords: buy, sell, acqui(sition,re), and spinoff

B: Firm is buying another company or unit

Keywords: buy, sell, acqui(sition,re), and spinoff 
$\mathrm{L}$ : Firm is target of leveraged buyout

Keywords: LBO, buyout

We focus on negative types of events since typically there are no significant flows from CDS to equity markets for positive information events (Acharya and Johnson (2007a)).

We anticipate that announcements that fall into categories A, E, and, to a lesser extent, S are likely to be value deteriorating. In other words, these announcements are likely to signal bad news for both creditors and equity holders of the company. Announcements of Type L often imply higher leverage and hence a lower value of debt for the firm, but might actually be good news for equity holders. Our intuition is that many of these LBO announcements reflect debt-deteriorating news. Categorizing Type B news as value-deteriorating or debt-deteriorating is less straight-forward.

For our sample period, the average firm has 1.0 announcements of Type A, 3.1 of Type E, 1.1 of Type S and 1.4 of Type B. We were able to compile a list of ten firms with LBO announcements for which we have access to all required data: CDS, OptionMetrics, CRSP, and Compustat. Details are provided in Table 2. For a subset of these ten firms, either Markit CDS rates were not available or the leveraged buyout was announced after the end of our Markit CDS sample on November 8, 2006. In these cases, we augment our existing data with default swap rates from Datastream. Datastream obtains CDS rate quotes from the DataVision CDS product by Credit Market Analysis (CMA). CMA receives CDS spreads from a range of market contributors. These contributors consist of both buy- and sell-side institutions active in the fixed-income markets such as asset managers, hedge funds, and banks. Market activity among CMA's sources depends on their need to buy or sell default protection. To ensure reliability of the quotes, we only use rates identified as actual trades, firm indications, or indications. CMA data is available from January 2003 until December 2006.

For each announcement category anmt $\in\{\mathrm{A}, \mathrm{E}, \mathrm{S}, \mathrm{B}, \mathrm{L}\}$, a dummy variable is constructed. In particular, for a given firm $i$, 
- $D_{\text {anmt }}^{\text {pre, }}(s)$ equals one if an announcement of type anmt occurred on date $t \in$ $\{s+1, s+2, s+3\}$ and zero otherwise,

- $D_{\text {anmt }}^{\mathrm{at}, i}(s)$ equals one if an announcement of type anmt occurred on date $t=s$ and zero otherwise,

- $D_{\text {anmt }}^{\text {post, }}(s)$ equals one if an announcement of type anmt occurred on date $t \in$ $\{s-1, s-2, s-3\}$ and zero otherwise.

To avoid overlapping dummy variables, we exclude news items released within seven days of a previous announcement of the same type.

In the last part of this section, we investigate the link between jumps in $C D S$, $I V, V l m C$ and $V \operatorname{lm} P$, and compare how they match up with the arrival time of firmspecific announcements of Types A, E, S, and B. Fig. 4 shows that upward jumps in implied volatilities coincide with upward jumps in CDS for less than ten percent of the latter. That value is even lower when comparing the timing of upward jumps in call-option volume or in put-option volume to that of upward jumps in credit spreads.

Fig. 5 plots the distribution of jumps in default swap rates and implied volatilities around announcement days for each news category. We find that announcements relating to accounting irregularities or fraud (Type A) and to lower-than-expected earnings or lowered forecasts (Type E) often lead to dramatic upward jumps in both CDS rates and implied volatilities. We observe jumps in spreads and jumps in IV on more than $13 \%$ of announcement dates of Type A, and on more than $7 \%$ of announcement dates of Type E. More interesting, however, is the fact that in more than $5 \%$ of the scenarios, a jump in prices can already be observed one day before the news is released. For announcement category B, this fraction is somewhat lower at $3 \%$ to $4 \%$. No clear pattern is established for news of Type S.

Fig. 6 plots the distribution of jumps in options volume around announcement days for each news category. As with derivatives prices, we find that announcements of Types A and E often lead to dramatic upward jumps in put and, to a lesser extent, call option volume. In particular, we observe that in almost $10 \%$ and more than $15 \%$ 
of the Type A and Type E scenarios, a large upward jump in put option volume can already be observed one day prior to the news release.

\section{The Cross-Correlation Structure between CDS, Options and Equity Markets}

We begin our empirical analysis by studying the cross-correlation structure between credit default swap, options and equity markets. Fig. 7 shows the pairwise crosscorrelation between daily percentage changes in CDS rates at time $t$ and daily percentage changes in implied volatilities at time $t+k$, for $k=-5,-4, \ldots, 4,5$. The top panel shows the results for the whole sample. The middle panel and the bottom panel display the results for the subset of firms with one or more Type A releases and with one or more Type L releases, respectively. In each panel, the cross-correlations for individual firms are averaged across firms.

We find, on average across all firms, a positive correlation between percentage changes in credit spreads and both present and past percentage changes in IV. The top panel in Fig. 7 documents a flow of information from the options market to the CDS market. As implied volatilities increase, contemporaneous and future prices of default protection decrease. When the whole sample is employed, the cross-correlation between relative CDS changes and future relative IV changes is still positive and significant for day $t+1$, even though it is substantially smaller in magnitude. The correlation structure for the subset of firms with Type A announcements is similar to that for the whole sample, except that the cross-correlation between CDS returns at time $t$ and IV returns at time $t+1$ is now almost 2.5 times as large as the corresponding value for the sample average. In other words, the middle panel in Fig. 7 shows that firms that were involved in accounting irregularities or fraud during our sample period show on average a larger flow of information from current CDS returns to IV returns one day later. For the subset of firms with LBO announcements in the bottom panel of the same plot, the positive relationship between percentage 
changes in credit spreads and percentage changes in implied volatilities disappears, except when comparing CDS returns at time $t$ to IV returns on date $t-2$. In any case, none of the estimates in the bottom panel are significant, a fact that is partially due to the fairly small number of firms (10) in our sample for which news of Type L were released.

Fig. 8 presents the correlation structure between daily percentage changes in CDS rates and daily stock returns. The results in the top panel show a negative average correlation between percentage changes in credit spreads and both present and past stock returns. This points to a flow of information from the equity market to the CDS market. As stock returns increase, contemporaneous and future prices for default protection decrease. When the whole sample is employed, the cross-correlation between relative CDS changes and future stock returns is essentially zero, which is in line with the findings in Acharya and Johnson (2007a). The panel for firms with Type A announcements, on the other hand, shows a small negative flow of information from the CDS market to the stock market. The correlation is greatest in magnitude, and statistically significant, for day $t+1$. The bottom panel of Fig. 8 is in striking contrast to both the top and the middle panel. For firms with a Type L announcement, the cross-correlation between percentage changes in CDS rates and past stock returns is substantially smaller in absolute values when compared to the top two panels, indicating that there is little to no flow of information from the equity market to the credit market. More importantly, the correlation between contemporaneous CDS and stock returns is now positive (and statistically significant). This finding differs dramatically from the results for the whole sample and for firms with Type A announcements. It is consistent with the notion that leveraged buyout announcements or rumors of a possible LBO deal often lead to higher leverage and hence higher credit spreads for the target firm, but are at the same time good news for its equity holders. We also find a small but positive flow of information from CDS returns to future stock returns (significant at 10\% level for time $t+1$ ). This evidence is in line with the hypothesis that insiders in CDS markets exploit information regarding future LBO 
announcements.

Finally, Fig. 9 plots the cross-correlation between daily percentage changes in IV and daily stock returns. In all three panels, there is a negative correlation between percentage changes in implied volatilities and present stock returns. When using all firms in our sample, that correlation is estimated to be -0.3. For firms with Type A announcements, the correlation between contemporaneous percentage changes in IV and stock returns is slightly larger in magnitude than for the whole sample, while for firms with Type L announcements it is substantially smaller in magnitude. A potential explanation for the latter finding is that the unconditional negative relationship between IV returns at time $t$ and stock returns at $t$ is reversed when LBO announcements are made. When the whole sample is used, the correlation between IV returns and future stock returns is essentially zero. (The average of the correlation estimates for IV returns at time $t$ and stock returns at time $t+k$, across $k=1, \ldots, 5$, is less than one percent.) When focusing on the first lag only, that is the correlation between IV returns at time $t$ and stock returns at time $t+1$, that value is estimated to be negative and statistically significant. From the middle and the bottom panel of Fig. 9 we find that this correlation is estimated to be larger in magnitude for firms with Type A announcements, and that it is essentially zero for firms with Type L announcements.

In summary, this preliminary evidence suggests that the information flow between credit and options markets can be significant in both directions, and that strength of the spillover effects in either direction is closely linked to the kind of news released for the firm. More importantly, significant cross-correlation between CDS returns and future stock returns may exist for firms that were subject to certain kind of news, and the sign of that relationship can be negative for firms with value-deteriorating news (e.g., Type A announcements) and positive for firms with debt-deteriorating news (e.g., Type L announcements). The magnitude of the correlation between percentage changes in implied volatilities and future stock returns also depends on the type of news a firm has been subject to, but it is generally smaller in absolute terms than 
the corresponding value for CDS returns and future stock returns.

\section{Information Flow between CDS and Options Markets}

In this section, we investigate the information flow between CDS and options markets. We pay particular attention to the conditional spillover effects around a number of credit- and options-market events and around specific news releases.

\subsection{Information Flow from CDS to Options Markets}

First, we analyze the information content of credit spreads for future movements in option-implied volatilities of the same firm. Specifically, we estimate the panel regression

$$
\begin{aligned}
\operatorname{IVrtn}_{t}^{i}=a+ & {\left[b+\sum_{z \in\{\text { pre,at,post }\}} b^{z} D_{\Delta C D S}^{z, i}(t)\right] \operatorname{CDSinnov}_{o}^{i}(t-1) } \\
+ & {\left[c+\sum_{z \in\{\text { pre,at,post }\}} c^{z} D_{\Delta C D S}^{z, i}(t)\right] \operatorname{IVrtn}_{t-1}^{i}+\epsilon_{t}^{i} }
\end{aligned}
$$

where CDSinnov ${ }_{o}^{i}$ are the innovations in the CDS market relative to the options market as defined in Section 2.2.1. We examine $b$ and $b^{z}, z \in\{$ pre, at, post $\}$, as measures of unconditional and conditional information flows from the CDS market to the options market. Results are provided in the first column of the top panel of Table 3. Our findings indicate that the unconditional flow of information from the CDS market to the options market is positive and statistically significant. The regression results predict that if CDS innovations increase by $10 \%$ during the previous trading day, current percentage changes in implied volatilities increase by $0.49 \%$. The estimate for $b^{\text {pre }}$ in the first column of the table indicates an average conditional spillover from CDS innovations to future options market returns of $1.3 \%$ during the three days leading up to a credit-market event. (Note that this estimate is not 
statistically different from zero for our sample period.) However, on the day of the adverse credit-market event and for the three days immediately following it, we find a negative conditional flow of information of $-3.4 \%$ and $-2.7 \%$, respectively, which is statistically significant for the latter case. This points to a significantly smaller total flow of information from the CDS market to the options market in the days following a dramatic increase in the firm's credit spreads.

A feature of the panel regression in (6) is that it forces all firms to have the same dynamic properties, except as captured by the conditioning introduced in the lagged response terms. To study the cross-firm variation in the response to creditmarket news, we now allow the information flow to vary depending on the firm's $(i)$ distance to default, (ii) implied volatility, and (iii) size. The later is computed as the market value of the firm's equity by multiplying CRSP share prices by number of shares outstanding. The size of firm $i$ is denoted by $S Z^{i}$ and reported in millions of U.S. dollars. This analysis addresses the possibility that our previous findings regarding the conditional spillover effects from CDS innovations to options market returns were actually driven by uncaptured variation in the other terms (the intercept or CDSinnov and IVrtn lag coefficients). To be specific, we extend the model in (6) to

$$
\begin{aligned}
& I V r t n_{t}^{i}=a^{i}+\left[b_{t}^{i}+\sum_{z \in\{\text { pre,at,post }\}} b^{z} D_{\Delta C D S}^{z, i}(t)\right] \operatorname{CDSinnov} v_{o}^{i}(t-1) \\
& +\left[c_{t}^{i}+\sum_{z \in\{\text { pre,at,post }\}} c^{z} D_{\Delta C D S}^{z, i}(t)\right] \operatorname{IVrtn}_{t-1}^{i}+\epsilon_{t}^{i},
\end{aligned}
$$

where

$$
\begin{aligned}
b_{t}^{i}=b & +b^{\mathrm{DD}}\left[D D_{t}^{i}-\operatorname{avg}_{j, s}\left(D D_{s}^{j}\right)\right]+b^{\mathrm{IV}}\left[\log \left(I V_{t}^{i}\right)-\operatorname{avg}_{j, s}\left(\log \left(I V_{s}^{j}\right)\right)\right] \\
& +b^{\mathrm{SZ}}\left[\log \left(S Z_{t}^{i}\right)-\operatorname{avg}_{j, s}\left(\log \left(S Z_{s}^{j}\right)\right)\right] .
\end{aligned}
$$

The term $c_{t}^{i}$ is defined in a similar fashion to ensure that any CDS innovations 
lag effects are not artifacts of unmodeled dynamics in the option price itself. Results are provided in the second column of the top panel of Table 3. Our findings indicate that the unconditional information flow from the CDS market to the options market is still positive and statistically significant. The regression results predict that if CDS innovations increase by $10 \%$ during the previous trading day, current percentage changes in implied volatilities increase by $0.5 \%$. There is a significant positive conditional spillover of $1.7 \%$ as the firm's distance to default decreases (and default probabilities increase) and of $3.7 \%$ as its log implied volatility increases. The size of the firm does not alter the flow of information in a significant way. On the day of an adverse credit-market event as well as for the three days immediately preceding and for the three days immediately following the event, we find a negative conditional spillover effect that is statistically significant for the latter case. While adding the three control variables leaves the estimate for $\hat{b}$ nearly unchanged, the estimates for the conditional CDSinnovo multipliers are now more negative.

Finally, we also account for sectoral and temporal effects to capture variations in the information flow that is common to all firms but not yet captured by distance to default, implied volatility, and size. This is accomplished by adding

$$
\sum_{\text {sectors }} b^{s} D^{s, i}+\sum_{\mathrm{q} \operatorname{trs}} b^{q} D_{t}^{q, i}
$$

to the right-hand side of (8). Here, $b^{s}$ and $b^{q}$ denote the dummy multiplier for sector $s$ and quarter $q$, respectively. The first quarter of 2002 and Basic Materials are the reference quarter and sector, respectively. Results are provided in the third column of the top panel of Table 3. For firms in our benchmark sector, the average quarterly unconditional information flow from the CDS market to the options market is $4.1 \%$, which is in line with the values reported for the earlier model specifications. This estimate is, at least on average, no longer statistically significant due to the reduced amount of data per quarterly dummy multiplier to be estimated. The estimates for the sectoral dummy variable multipliers (not reported) indicate that firms in the Con- 
sumer Goods $(+4.1 \%)$, Telecommunications $(+5.6 \%)$, and Utilities $(+6.1 \%)$ sectors exhibit a significantly higher flow of information. Even after controlling for sectoral and temporal effects, there still is a significant positive conditional spillover of $1.4 \%$ as the firm's distance to default decreases and $5.5 \%$ as log implied volatilities increase. As before, the size of the firm shows no significant effect. Similarly, when an adverse credit-market event occurs as well as for the three days immediately preceding and for the three days immediately following the event, we still find a negative conditional spillover effect that is statistically significant for the latter case. This leads to a diminished total flow of information from CDS innovations to options market returns around dramatic increases in the firm's CDS rates.

The remaining columns in the top panel of Table 3 show the estimation results for similar sets of panel regressions after replacing $D_{\Delta C D S}^{\bullet}$ with $D_{\Delta I V}^{\bullet}, D_{\Delta V l m C}^{\bullet}$, and $D_{\Delta V l m P}^{\bullet}$, respectively. Ignoring for a moment estimates for the options-market-event dummy multipliers, the findings with regard to the unconditional and conditional information flow remain roughly the same. The only difference is that now we observe a significant positive conditional spillover effect for large firms. What is of interest is that at the time of and for the three days immediately following dramatic increases in implied volatilities we find a significant incremental flow of information from the CDS market to the options market of $44.4 \%$ and $2.9 \%$, respectively.

As shown in Fig. 4, upward jumps in implied volatilities coincide with adverse credit market events for less than ten percent of the latter events. That figure is even lower when comparing the timing of upward jumps in call-option volume or in put-option volume to that of upward jumps in credit spreads. To improve the interpretability of our estimates for the event-condition dummy multipliers, we therefore now replace the credit-market event dummy $D_{\triangle C D S}^{z, i}$ with dummy variables that identify the certain types of firm-specific announcements. In particular, we estimate the 
panel regression

$$
\begin{aligned}
\operatorname{IVrtn}_{t}^{i}=a^{i} & +\left[b_{t}^{i}+\sum_{z \in\{\text { pre,at,post }\}} b^{z} D_{\text {anmt }}^{z, i}(t)\right] \operatorname{CDSinnov}_{o}^{i}(t-1) \\
+ & {\left[c_{t}^{i}+\sum_{z \in\{\text { pre,at,post }\}} c^{z} D_{a n m t}^{z, i}(t)\right] \operatorname{IVrtn}_{t-1}^{i}+\epsilon_{t}^{i} . }
\end{aligned}
$$

The top panel of Table 4 reports the parameter estimates and $t$-statistics for each announcement type anmt $\in\{\mathrm{A}, \mathrm{E}, \mathrm{S}, \mathrm{B}\}$. The results for Type $\mathrm{L}$ announcements are shown in the first three columns of Table 7. We again run the three nested panel regressions

I: $a^{i}=a, b_{t}^{i}=b$, and $c_{t}^{i}=c$,

II: $b_{t}^{i}$ and $c_{t}^{i}$ are specified as in (8), and

III: $b_{t}^{i}$ and $c_{t}^{i}$ are given as in (8) plus (9).

Results for the unconditional flow of information and for spillover effects conditioned on distance to default and on implied volatility are similar to those presented in Table 3. For specification III, we estimate the conditional flow of information from CDS innovations to options market returns for large firms to be positive and significant. (The estimates for Type E and Type L announcements are significant only at the $10 \%$ level.) When using specific types of news instead of dramatic upward jumps in credit spreads to pin down when adverse credit-market events occur we are able to establish a strong positive conditional flow of information from the CDS market to the options market on the day negative earnings announcements are made. Expanding the window to the week around a Type E news release, we still find a positive average incremental spillover effect of $\left(3 b^{\text {pre }}+b^{\text {at }}+3 b^{\text {post }}\right) / 7$ equal to $2.5 \%$ for the full model (specification III). Another interesting observation can be made for Type $\mathrm{L}$ news. The estimates in Table 7 point to a positive and significant conditional flow of information from CDSinnov s $_{\text {to }}$ future IVrtn during the three-day period prior to a LBO announcement. This incremental flow of information is reversed, however, 
on the day of the announcement and during the three-day period following the news release.

\subsection{Information Flow from the Options Market to the CDS Market}

To investigate the reverse flow of information from the options market to the CDS market, we regress daily CDS returns on innovations in implied volatilities using different credit- and options-market condition dummies. In a panel-data regression setting, we first estimate the model

$$
\begin{aligned}
C D S r t n_{t}^{i}=a^{i} & +\left[b_{t}^{i}+\sum_{z \in\{\text { pre,at,post }\}} b^{z} D_{\Delta I V}^{z, i}(t)\right] \operatorname{IVinnov}_{c}^{i}(t-1) \\
+ & {\left[c_{t}^{i}+\sum_{z \in\{\text { pre,at,post }\}} c^{z} D_{\Delta I V}^{z, i}(t)\right] \operatorname{CDSrtn}_{t-1}^{i}+\epsilon_{t}^{i}, }
\end{aligned}
$$

for the three nested specifications I, II, and III of $a^{i}, b_{t}^{i}$ and $c_{t}^{i}$ described above.

Results are provided in the bottom panel of Table 3. After isolating innovations in individual implied volatilities, we find that the unconditional flow to the CDS market is positive at a transmission rate of more than $3 \%$ for the full model. Our estimates for the sector dummy multipliers (not reported) indicate that only Industrial firms have a significantly higher transmission rate $(+2.4 \%)$. Even after controlling for sectoral and temporal effects, there is still a significant positive conditional spillover effect from IVinnov $v_{c}$ to future CDS returns for firms with high implied volatilities $(+7.6 \%)$. In contrast to the results in Section 4.2, the incremental spillover effect from options to CDS markets seems to be larger for smaller companies and for firms with higher credit ratings. For example, if a firm's distance to default increases from 1.88 (the sample average across all firms and time) to 2.88, and hence Merton (1974) one-year default probabilities decrease from 0.03 to 0.002 , the flow of information from options to credit markets increases by 0.3 percent. Similarly, when the log size of the firm increases from 9.33 (the sample average across all firms and time) to 10.33 , the spillover effect decreases by -0.3 percent. Both the distance-to-default 
and firm-size coefficient estimates are significant for model specification II. Although the economic impact of these two condition variables remains the same, they are no longer statistically significant for the full model, a fact that is partially due to the reduced amount of data per variables to be estimated for specification III.

For the seven-day period around a dramatic upward jump in a firm's implied

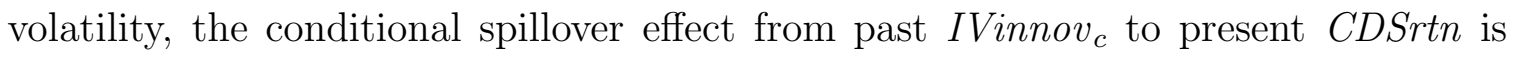
positive and statistically significant with an average daily incremental transmission rate of $\left(3 b^{\text {pre }}+b^{\text {at }}+3 b^{\text {post }}\right) / 7$ equal to $1.7 \%$ for the full model. It is of particular interest that during the three days prior to such an option-market event, percentage changes in credit spreads absorb on average an additional $2.3 \%$ of the IV innovations of the previous trading day, even after controlling for the firm's size, credit quality, idiosyncratic volatility and sector, as well as for other temporal effects. This estimate is statistically different from zero.

The remaining columns in the bottom panel of Table 3 show the estimation results for the panel regressions in (11), after replacing $D_{\Delta I V}^{\bullet}$ with $D_{\Delta C D S}^{\bullet}, D_{\Delta V l m C}^{\bullet}$, and $D_{\Delta V l m P}^{\bullet}$, respectively. Except for the event dummy multipliers, the findings with regard to the unconditional and conditional information flow remain roughly the same. In addition, we detect an incremental flow of information from the options market to the CDS market of about $1.6 \%$ per day during the three days prior to large jumps in credit spreads (column three), and a significant conditional spillover of $2.3 \%$ for the three days prior to a dramatic increase in put-options volume (column twelve). In that sense, we detect a significant incremental flow of information from the options market to the credit market a few days prior to adverse news being revealed in derivatives markets.

As in Section 4.1, we proceed to investigate the information revelation from the options market to the credit market around firm-specific news releases by replacing $D_{\Delta I V}^{z, i}(t)$ in (11) with $D_{\text {anmt }}^{z, i}(t)$ for anmt $\in\{A, E, S, B, L\}$. Results for the unconditional flow of information and for spillover effects conditioned on distance to default, implied volatility and firm size are reported in the bottom panel of Table 4 for Type 
A, E, S and B news, and in columns 4 through 6 of Table 7 for LBO announcements. They are similar to those presented in the bottom panel of Table 3.

With regard to the announcement dummy multipliers, the parameter estimates shown in Tables 4 and 7 identify strong incremental effects for announcements of Type A (before and at news release), Type S (before announcement) and Type L (before announcement). For announcements of Type S and L, an initial positive conditional spillover is partially reversed when and just after the news is released. The results for news relating to accounting irregularities or fraudulent behavior (Type A announcements) are of particular interest. They indicate that the average conditional flow of information from options markets to credit markets during the period that starts three days prior to the announcement and ends three days after the news is released, $\left(3 b^{\text {pre }}+b^{\text {at }}+3 b^{\text {post }}\right) / 7$, amounts to $14.7 \%$. For the median sector in our sample, that is more than six times the size of the unconditional flow of information from options to CDS markets.

In summary, we find that $(i)$ investors absorb information revealed in the CDS market into prices of equity options within a few days and vice versa, (ii) the incremental conditional information flow from the CDS market to the options market is significant for high-yield and for highly volatile firms, but is reduced in the days following a dramatic increase in credit spreads, and (iii) there is a strong conditional spillover from the options market to the CDS market during the week around a dramatic increase in implied volatility, as well as for highly volatile firms.

Running the horse race between the credit market and the options market shows that in general there is no clear winner: At least at the daily level, the options market seems to reveal information at the same time as the credit market. In particular, we find only limited support for the hypothesis that credit spreads contain information about adverse firm-specific developments before that information is reflected in options prices, with the exception of times when negative earnings announcements are made. If anything, the options market sometimes seems to react in advance of the credit market, especially during the days leading up to dramatic increases in im- 
plied volatilities or in put-options volume, and before accounting scandals break or fraudulent behavior is detected.

\subsection{Robustness Checks}

To check whether the leading relation identified in Section 4.2 is merely a transient effect, possibly due to some short-term price pressure from the hedging activity of options-market participants in the credit market, we experiment with more than one lag by replacing the conditional response term in (11) with

$$
\sum_{k=1}^{5}\left[b_{k}+\sum_{z \in\{\mathrm{pre}, \mathrm{at}, \mathrm{post}\}} b_{k}^{z} D_{\Delta I V}^{z, i}(t)\right] \operatorname{IVinnov}_{o}^{i}(t-k) .
$$

We find no significant contribution to the unconditional or the conditional flow of information at any lag other than the first one. (Results not reported.) As an additional robustness check, we also replaced $D_{\Delta I V}^{\mathrm{pre}, i}$ and $D_{\Delta I V}^{\mathrm{post}, i}$ with dummy variables that were turned on for more than three days-for example, for five or seven days. Again, we did not find any significant deviation from the results reported previously.

Yet another specification would be to leave $D_{\Delta I V}^{\text {post }, i}$ turned on throughout the remainder of the sample period. We decided not to use such a specification because it would make it difficult to disentangle the unconditional information flow from that around event dates, particularly because many instances of dramatic one-day increases in implied volatilities occur early in the sample (for example, in the second half of 2002 following the Worldcom disaster). In addition, the current definition of the volatility-condition dummy variables allows for a more natural interpretation of the effects of more than one upward jump in volatility for the firm during our sample period. Similar robustness checks were performed for the results in Section 4.1. Reassured by the outcome of these tests, we interpret $\left(3 b^{\text {pre }}+b^{\text {at }}+3 b^{\text {post }}\right) / 7$ as a measure of permanent information flow conditioned on adverse credit-market or options-market events. 


\section{Information Flow from CDS and Options Mar- kets to the Equity Market}

In this section, we quantify the joint contribution of the CDS market and the options market to price discovery relative to the stock market. Our panel-data regression model is specified as

$$
\begin{aligned}
\text { STKrtn }_{t}^{i}=a^{i}+ & {\left[b_{t}^{i}+\sum_{z \in\{\text { pre,at,post }\}} b^{z} D_{\text {cond }}^{z, i}(t)\right] \operatorname{CDSinnov~}_{e, o}^{i}(t-1) } \\
+ & {\left[d_{t}^{i}+\sum_{z \in\{\text { pre,at,post }\}} d^{z} D_{\text {cond }}^{z, i}(t)\right] \operatorname{IVinnov}_{e}^{i}(t-1) } \\
+ & {\left[c_{t}^{i}+\sum_{z \in\{\text { pre,at,post }\}} c^{z} D_{\text {cond }}^{z, i}(t)\right] \operatorname{STKrtn}_{t-1}^{i}+\epsilon_{t}^{i}, }
\end{aligned}
$$

where cond $\in\{\Delta C D S, \Delta I V, \Delta V \operatorname{lm} C, \Delta V \operatorname{lm} P\}$. Whereas IV innovations are measured relative to the equity market only (news in the options market that has not yet been revealed in the equity market), CDS innovations are defined relative to both the stock market and the options market (news in the CDS market that has not yet been revealed in either the equity market or the options market). Using CDSinnov $v_{e, o}$ instead of CDSinnov in $_{e}(13)$ enables us to measure the CDS market's contribution to price discovery relative to both the stock market and the options market.

The recognition of two types of announcements - news that widens credit spreads can be either value deteriorating (bad news for both equity and debt holders) or debt deteriorating (bad news for debt holders but good news for equity holders) - is advantageous not just in detecting a conditional flow of information from the CDS and the options markets to the equity market, but also in measuring the sign and magnitude of such incremental spillover effects correctly. We therefore replace the credit- and options-market event dummies with dummy variables that identify the type of announcement. In particular, we re-estimate the panel regression in (13) after replacing $D_{\text {cond }}^{\bullet}$ with $D_{\text {anmt }}^{\bullet}$, for anmt $\in\{\mathrm{A}, \mathrm{E}, \mathrm{S}, \mathrm{B}, \mathrm{L}\}$. 
Tables 5, 6 and 7 report the estimation results for three nested model specifications:

$\mathrm{I}: a^{i}=a, b_{t}^{i}=b, d_{t}^{i}=d$, and $c_{t}^{i}=c$,

II: $b_{t}^{i}, d_{t}^{i}$, and $c_{t}^{i}$ are specified as in (8), and

III: $b_{t}^{i}, d_{t}^{i}$, and $c_{t}^{i}$ are given as in (8) plus (9).

Focusing on the full model (specification III), we now describe our findings for the CDS innovation and for the IV innovation dummy multipliers in (13).

\subsection{Information Flow from the CDS Market to the Equity Market, After Controlling for the Information Content of Option Prices}

We first discuss the estimation results for the information flow from $\operatorname{CDSinnov}_{e, o}$ to future STKrtn, after controlling for news revealed in the options market. Table 5 shows that for firms in our benchmark sector (Basic Materials), the unconditional flow of information from the credit market to the equity market is very small: on the order of $-0.1 \%$ to $-0.7 \%$, depending on the conditioning variable. It is significantly more negative $(-1.7 \%$ to $-2.8 \%)$ only for Utilities firms. The incremental spillover effect from CDS to equity markets is more negative for high-IV and for large firms and increases in absolute value with the company's default risk, although the latter estimate loses its statistical significance when taking into account sectoral and quarterly effects.

This evidence suggests that under certain market conditions, price discovery in the credit markets precedes that in the equity market. Acharya and Johnson (2007a) suggest that this is likely due to the activity of insiders with access to non-public information and support their hypothesis by providing evidence that more insiders lead to a greater information flow from the CDS market to the equity market. The authors use the number of banking relationships for the firm - the number of commercial banks with an ongoing lending relationship with the company — as a proxy for the number of insiders. Since the data on banking relationships is not available to us, we 
make use of the fact that there is a strong monotonic relationship between the number of banking relationships and the size of the firm, also shown by Acharya and Johnson (2007a). In the sense that the firm-size dummy multiplier for CDSinnov CDo $_{\text {in }}$ (13) is estimated to be significant and negative, our results in Table 5 support the hypothesis that the information flow from CDS markets to equity markets is stronger as the number of insiders increases. The contribution over the existing literature is that we have verified that this statement holds even after controlling for the information content of option prices.

The results in Table 5 indicate an additional negative flow of information from the CDS market to the equity market during the seven-day period around a dramatic increase in credit spreads. Average daily transmission rates become more negative by $\left(3 b^{\text {pre }}+b^{\text {at }}+3 b^{\text {post }}\right) / 7=-0.6 \%$. With regard to upward jumps in implied volatilities, call-option and put-option volume, the incremental spillover effect from CDSinnov $v_{e, o}$ to future STKrtn amounts to $-2.5 \%,-1.4 \%$ and $0.5 \%$ respectively. Note that for the average firm in our sample, the unconditional and conditional flow of information from the CDS market to the equity market is estimated to be negative, implying that adverse firm-specific news revealed in credit markets tend to reduce future returns on the firm's equity.

Next, we replace the credit- and options-market event dummies in (13) with dummy variables that pin down the timing of actual firm-specific news releases, which allows us to investigate to what extent the incremental information revelation from the CDS market to the equity market depends on the type of announcement. Results are summarized in Table 6 for announcement types A, E, S and B, and in Table 7 for Type L news. Except for the event dummy multipliers, the findings with regard to the unconditional and conditional information revelation are roughly as presented in Table 5. Fig. 10 shows the estimates for the quarterly dummy multipliers for innovations in CDS rates. Any common time variation in the spillover effects that cannot be accounted for by changes in credit quality, implied volatility or firm size is captured by this time series. What we find is that transmission rates from credit 
to equity markets are substantially more negative in the second half of our sample period (since 2004).

Even after controlling for the information contained in option prices, we find a significant conditional spillover from the CDS market to the equity market when announcements of Type A or E are made, for the three-day period leading up to a Type $\mathrm{S}$ or Type L announcement, and for the three-day period following a news release of Type B. The results for lower-than-expected earnings or lowered earnings forecasts (Type E announcements) are particularly interesting. They show that the average conditional flow of information from CDS to equity markets during the period that starts three days prior to the announcement and ends three days after the news is released, $\left(3 b^{\text {pre }}+b^{\text {at }}+3 b^{\text {post }}\right) / 7$, amounts to $-3.7 \%$. For the average sector in our sample, that is almost six times the size of the unconditional flow of information from CDS to equity markets. Together with the evidence presented in Section 4.1, our findings suggest that CDS markets discover information regarding lower-than-expected earnings or earnings forecasts to be lowered before that information is revealed through option or equity prices, and at least one day or even a few days before the news is publicly released. At the time a Type E announcement is made and for the three-day period thereafter, we find both a strong positive incremental spillover from credit to options markets and a strong negative incremental spillover from CDS to equity markets.

Another striking finding is the positive sign for the incremental flow of information from credit to equity markets around the time when leveraged buyout deals are announced. The positive sign is in line with our intuition that LBOs are debtdeteriorating news, meaning good news for equity holders and bad news for creditors of the buyout target. The average conditional flow of information from CDS to equity markets during the week around the news release equals $+5.2 \%$. For the three-day period leading up to a Type L announcement, the incremental rate of transmission is significant and amounts to $+10.0 \%$. For the average firm in our sample, this implies that the total flow of information from CDSinnov ${ }_{e, o}$ to future STKrtn is positive during that time. 
During the seven-day window around a Type S announcement date, the average conditional flow of information from the credit market to the equity market is roughly 4.6 times the size of the unconditional flow for the average sector. In comparison, that figure amounts to 2.8 and -4.1 for Type B and Type A announcements, respectively. The negative sign for the latter is due to the fact that for the three-day period leading up to a Type A news release, the conditional information flow from credit to equity markets is positive. The direction of that conditional spillover changes, however, on the day of a Type A announcement, and it remains negative for the three-day period following the news release.

To summarize our findings so far: even after controlling for news revealed through options prices, the CDS market leads the equity market at times when certain adverse credit-market events occur, for example when news of lower-than-expected earnings is revealed or when leveraged buyout announcements are made. Using event dummies for specific types of news instead of credit or options-market condition dummies allows us to distinguish a leading relationship with a negative incremental spillover effect (as observed for value-deteriorating news of Type E) from that with a positive conditional flow of information (e.g., for debt-deteriorating news of Type L).

Finally, we investigate to what extent the estimation results in Tables 7, 5 and 6 change if we do not account for news revealed in the options market. Specifically, we run a panel-data regression of the form

$$
\begin{aligned}
\operatorname{STKrtn}_{t}^{i}=a^{i} & {\left[b_{t}^{i}+\sum_{z \in\{\text { pre,at,post }\}} b^{z} D_{\bullet}^{z, i}(t)\right] \operatorname{CDSinnov}_{e}^{i}(t-1) } \\
+ & {\left[c_{t}^{i}+\sum_{z \in\{\text { pre,at }, \text { post }\}} c^{z} D_{\bullet}^{z, i}(t)\right] \operatorname{STKrtn}_{t-1}^{i}+\epsilon_{t}^{i}, }
\end{aligned}
$$

where $\bullet\{\Delta C D S, \Delta I V, \Delta V l m C, \Delta V l m P, \mathrm{~A}, \mathrm{E}, \mathrm{S}, \mathrm{B}, \mathrm{L}\}$. Note that in this case, CDS innovations are defined relative to the stock market only (news in the CDS market that has not yet been revealed in the equity market).

Ignoring for a moment estimates for the event dummy multipliers, we find that 
the (unreported) results for (14) are similar to those for (13). But on days with dramatic upward jumps in credit spreads, the conditional spillover from the CDS market to the equity market is estimated to be more than $40 \%$ higher in absolute values when ignoring the options market, decreasing from -0.032 for (13) to -0.045 for (14). As a results, the average daily conditional flow of information from CDS to equity markets during the seven-day window around an upward jump in CDS almost doubles from $-0.6 \%$ to $-1.0 \%$. Similar observations can be made for Type E and Type L announcements. For Type E news, the average conditional flow is now also more negative, decreasing from $-3.7 \%$ for (13) to $-4.2 \%$ for (14). Moreover, when options-market news are not taken into account, all three Type E announcement dummy multipliers $b^{\text {pre }}, b^{\text {at }}$ and $b^{\text {post }}$ (instead of just $b^{\text {at }}$ ) are estimated to be statistically significant. For days when Type L announcements are made, the estimated incremental transmission rate changes from 0.038 for (13) to 0.115 if the options market is ignored, an increase of more than $200 \%$.

In conclusion, while many of the results regarding unconditional and conditional flows of information from credit to equity markets that are obtained for (14) still remain valid when controlling for option-market news as in (13), the estimated absolute value of incremental spillover effects around adverse credit-market events is likely to have an upward bias under the former specification. This result supports the hypothesis that the CDS market provides information to equity investors about adverse credit-market events in addition to or more precisely than what the options market reveals.

\subsection{Information Flow from the Options Market to the Equity Market}

We now turn our attention to the information flow from IVinnov $v_{e}$ to future stock returns. Even though CDSinnov $v_{e, o}^{i}$ is orthogonal to the information contained in contemporaneous IVinnov ${ }_{e}^{i}$ and $S T K r t n^{i}$ (see Section 2.2.1 for definitions), in (13) some interaction between these three terms may arise through their joint interaction with $D_{\text {cond }}^{z, i}$. However, we have verified that the results regarding information revelation from options to equity markets derived from the joint model in (13) do not change 
in any significant way if credit markets were ignored. This allows us to focus our discussion of results on the former.

Table 5 shows that the unconditional information revelation from the options market to the equity market is also very small: on the order of $-0.1 \%$ to $-0.4 \%$ for the benchmark sector, depending on the conditioning variable. It is significantly more negative only for Oil and Gas firms $(-1.8 \%$ to $-2.1 \%)$. The conditional spillover effects from options to equity markets are stronger for highly volatile firms. In contrast to the results for credit markets, the conditional flow of information from the options market to the equity market is significantly more pronounced for smaller firms. In other words, an increase in IV innovations has a larger impact on stock returns of a small firm than on those of larger companies. The riskiness of the firm, as measured by its distance to default, has only a small, insignificant impact.

The results in Table 5 show no additional flow of information from the options market to the equity market during the week around an upward jump in implied volatility. Average daily transmission rates are essentially zero (-0.1\%). With regard to upward jumps in call-option volume, put-option volume and credit spreads, the incremental spillover effect from IVinnov $v_{e}$ to future STKrtn amounts to $-1.4 \%, 0.2 \%$ and $-1.5 \%$ respectively.

A better interpretation of the sign and the magnitude of the conditional information flow around adverse credit or options-market events can be obtained when the conditioning dummies in (13) are replaced by dummy variables for specific types of news. The results in Tables 6 and 7 show that the findings with regard to the unconditional and conditional information revelation - except for the event dummy multipliers - are roughly the same as in Table 5 .

It is important to point out that there are no significant negative conditional spillover effects from the options market to the equity market around announcement dates for Type A, E, S or B news, at least not for the full model (specification III). Although we detect a significant positive incremental transmission of information when announcements of Type S are made, the incremental information flow has the oppo- 
site sign during the three-day period preceding and the three-day period following the disclosure. This results in a small but negative average conditional flow of information from options to equity markets of $-0.5 \%$ during the week around a Type $\mathrm{S}$ news release date. Despite the strong evidence presented in Section 4.2 that the options market discovers information regarding accounting scandals or fraudulent behavior (Type A announcements) before that news is revealed through default swap rates, the results in Table 6 suggest that this information has to manifest itself in the CDS market before it is fully appreciated by the equity market.

As in Section 4.2, we do find a positive sign for the incremental flow of information from options to equity markets when LBO announcements are made. The average conditional spillover during the week around the news release amounts to an impressive $+7.7 \%$. On the date the Type L news breaks, the incremental rate of transmission is significant and particularly large at $+47.5 \%$, reversing the sign of the

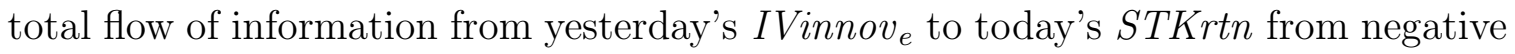
to positive for the average firm in our sample.

\subsection{Summary of Results}

Our empirical evidence shows that

(a) there is a positive unconditional flow of information from the CDS market to the options markets and vice versa.

(b) at the daily level, the options market often reveals information at the same time as the credit market does (e.g., for Type B and Type L news). For announcements of Type A or S, option prices even react in advance of credit spreads. An exception are Type E news, for which the CDS market leads the options market.

(c) the unconditional flow of information from the credit market to the equity market is negative but very small. The same holds true for the information flow from the options market. 
(d) there is a strong conditional spillover from CDS to equity markets for announcements of Type E, S and L, even after controlling for the news revealed in options prices.

(e) except for Type L news, we do not detect any incremental spillover effects from options to equity markets for the other four types of announcements. And even for LBO announcements, the equity market first reacts to news in credit spreads and only afterwards to movement in options prices.

For all five types of announcements that we analyze we find that the equity market does not respond to news in option prices unless that information has manifested itself in the CDS market. A potential explanation is that options are more likely to trade on unsubstantiated rumors than default swaps are, setting off so-called "piggyback" buying from options traders hoping to catch a lucky break. Berman and Ng (2006) argue that in many of these instances, such as for Starwood Hotels \& Resorts Worldwide Inc., the trading stir ends in a whimper and no deal ever materializes. As a result, if there is a sudden upward jump in implied volatility that is not accompanied by a reaction in credit spreads that day or shortly afterwards, equity-market participants may be more likely to believe that the change in option prices was due to unsubstantiated rumors rather than new information. In the next section, we build on this concept and develop a simple framework of information arrival and transmission that is rich enough to generate the stylized facts described in (a) through (e).

\section{A Simple Model of Information Arrival and Trans- mission}

To improve the interpretability of our empirical results, we propose a model of information arrival and transmission for credit, options and equity markets that is, although very simply, rich enough to capture the essence of the empirical findings summarized in Section 5.3. For a given firm, let $D_{t}^{E}$ denote a dummy variable that 
equals one if news of an event that is bad for the firm's creditors is released at $t$, and zero otherwise. Similarly, let $D_{t}^{R}$ denote a dummy variable that equals one if unsubstantiated rumors - that are not indicative of any real event-are spread at time $t$. To keep things simple we assume that $D_{t}^{E}$ and $D_{t}^{R}$ are independent of each other, and of all information available up to day $t-1$. Suppose that new information is incorporated into credit spreads according to

$$
\begin{aligned}
\operatorname{CDSrtn}_{t}= & \kappa^{c}+\kappa^{c, c} \operatorname{CDSrtn}_{t-1}+\kappa^{c, o} \operatorname{IVrtn}_{t-1}+\kappa^{c, e} \operatorname{STKrtn}_{t-1}+\varepsilon_{t}^{c} \\
& +\kappa^{c, E} D_{t}^{E}+\kappa_{1}^{c, E} D_{t+1}^{E}+\kappa_{2}^{c, E} D_{t+2}^{E}-\kappa^{c, o} \kappa^{o, R} D_{t-1}^{R} .
\end{aligned}
$$

where the $\varepsilon_{t}^{c}$ s are zero-mean random variables with constant standard deviation $\sigma^{c}$, independent of $D_{t}^{E}, D_{t}^{R}$ and all information available up to $t-1$. In addition to relating to past CDS, options and stock returns, CDS rates jump upward at time $t$ if adverse credit-market news is announced on that day, or if such news will be released publicly within the next two days. The latter is allowing for the fact that credit market participants may have access to insider information at time $t$ about adverse events in the near future. The non-negative scalars $\kappa^{c, E}, \kappa_{1}^{c, E}$ and $\kappa_{2}^{c, E}$ capture the response of the credit market to current news and to insider information.

Percentage changes in implied volatilities are assumed to follow a similar pattern, with the additional possibility of trading on rumors. One day after an unsubstantiated rumor was spread, both the options market and the credit market correct for that fact.

$$
\begin{aligned}
\operatorname{IVrtn}_{t}=\kappa^{o} & +\kappa^{o, c} \operatorname{CDSrtn}_{t-1}+\kappa^{o, o} \operatorname{IVrtn}_{t-1}+\kappa^{o, e} \operatorname{STKrtn}_{t-1}+\varepsilon_{t}^{o} \\
& +\kappa^{o, E} D_{t}^{E}+\kappa_{1}^{o, E} D_{t+1}^{E}+\kappa_{2}^{o, E} D_{t+2}^{E}+\kappa^{o, R} D_{t}^{R}-\kappa^{o, o} \kappa^{o, R} D_{t-1}^{R}
\end{aligned}
$$

One could easily extend the set-up in (15) and (16) to the case where the constant dummy multiplier $\kappa_{1}^{c, E}$ is multiplied with a zero-one random variable that captures whether or not credit spreads move at time $t$ given insider information regarding news to be revealed publicly the next day. Similarly for the non-negative scalars $\kappa^{c, E}$, 
$\kappa_{2}^{c, E}, \kappa^{o, E}, \kappa_{1}^{o, E}, \kappa_{2}^{o, E}$ and $\kappa^{o, R}$. In addition, credit markets may also trade on rumors, although possibly to a lesser extent than options markets.

We assume that new information is incorporated into equity prices according to

$$
\begin{aligned}
\operatorname{STKrtn}_{t}=\kappa^{e} & +\kappa^{e, c} C D \operatorname{Srtn}_{t-1}+\kappa^{e, o} \operatorname{IVrtn}_{t-1}+\kappa^{e, e} \operatorname{STKrtn}_{t-1}+\varepsilon_{t}^{e} \\
& +\gamma \kappa^{e, E} 1_{\left\{C_{t}>0\right\}}+\kappa^{e, E} D_{t}^{E} 1_{\left\{C_{t-1}=0\right\}}+(1-\gamma) \kappa^{e, E} D_{t}^{E} 1_{\left\{C_{t-1}>0\right\}} \\
& -\kappa^{e, o} \kappa^{o, R} 1_{\left\{\bar{C}_{t}>0\right\}}
\end{aligned}
$$

where $\varepsilon_{t}^{c}, \varepsilon_{t}^{o}$ and $\varepsilon_{t}^{e}$ are correlated with correlation parameters $\rho^{c, o}, \rho^{c, e}$ and $\rho^{o, e} . C_{t}$ is a dummy variable that equals one at time $t$ if credit spreads exhibited a dramatic upward jump the previous day even though no announcements were made either yesterday or today. In other words, $C_{t}=1$ if $C D S r t n_{t-1}-\left(\kappa^{c}+\kappa^{c, c} C D \operatorname{Srtn}_{t-2}+\right.$ $\left.\kappa^{c, o} \operatorname{IVrtn}_{t-2}+\kappa^{c, e} S T K r t n_{t-2}+\varepsilon_{t-1}^{c}\right)>0$ and $D_{t-1}^{E}=D_{t}^{E}=0$. If equity-market participants cannot observe past values of $\varepsilon^{c}$, or if $\kappa^{c}, \kappa^{c, c}, \kappa^{c, o}$ or $\kappa^{c, e}$ are unknown, the outcome of $C_{t}$ can still be approximated by assuming $\varepsilon_{t-1}^{c}=0$ and by using the past history of asset returns to compute OLS estimates for the unknown parameters. Similarly, $\bar{C}_{t}$ is a dummy variable that equals one if implied volatilities exhibited a dramatic upward jump at $t-1$ even though credit spreads did not jump upwards and no news was released yesterday, that is, $\bar{C}_{t}=1$ if $\operatorname{IVrtn}_{t-1}-\left(\kappa^{o}+\kappa^{o, c} C D \operatorname{Srtn}_{t-2}+\kappa^{o, o} \operatorname{IVrtn}_{t-2}+\kappa^{o, e} \operatorname{STKrtn}_{t-2}+\varepsilon_{t-1}^{o}\right)>0, \operatorname{CDSrtn}_{t-1}-$ $\left(\kappa^{c}+\kappa^{c, c} C D \operatorname{Srtn}_{t-2}+\kappa^{c, o} \operatorname{IVrtn}_{t-2}+\kappa^{c, e} \operatorname{STKrtn}_{t-2}+\varepsilon_{t-1}^{c}\right)=0$ and $D_{t-1}^{E}=0$. The sign of $\kappa^{e, E}$ determines whether the adverse news identified by $D_{t}^{E}$ is value-deteriorating $\left(\kappa^{e, E}<0\right)$ or debt-deteriorating $\left(\kappa^{e, E}>0\right)$.

The specification of stock returns in (17) captures the notion that investors in equity markets are strongly adverse to trading on rumors. Prices will adopt to new information only when it is publicly announced (that is, $D_{t}^{E}=1$ ) or when strong upward jumps in credit spreads have occurred the previous day even though no news was released at that time $\left(C_{t}=1\right)$. The latter is interpreted by stock-market participants as a signal of insider activity in credit markets, and we assume that equity 
markets react to that information with a one-day delay by adjusting stock returns by $\gamma \kappa^{e, E}$ the next day. In our implementation, we use $\gamma=\kappa_{2}^{c, E} /\left(\kappa^{c, E}+\kappa_{1}^{c, E}+\kappa_{2}^{c, E}\right)$ to account for the relative strength of the CDS-market signal. In contrast, if dramatic upward jumps in IV occur without contemporaneous news announcements or upward jumps in credit spreads, we assume that equity investors act very conservatively: they assume that these jumps were due to rumors rather than to options markets revealing new information prior to a public announcement and before CDS markets do. Equity investors are not in a position to directly verify at time $t$, whether or not the abnormal options-market trading on the previous day was caused by unsubstantiated rumors. They revise their beliefs regarding an options-market signal only after observing a subsequent upward jump in credit spreads, or once actual news is disclosed. Note that for $\kappa_{1}^{c, E}=\kappa_{2}^{c, E}=0$, there is no insider activity in credit markets, and that the same holds true for the options market if $\kappa_{1}^{o, E}=\kappa_{2}^{o, E}=0$.

In what follows we perform a simulation study of the model framework proposed in (15) through (17). Table 8 lists the set of model specifications for which we run a Monte Carlo analysis. Specifications M1 through M9 establish benchmark scenarios for the arrival and flow of information for the three markets, and M10 through M12 are designed to mimic the empirical findings for specific announcement types.

Given parameter values, we first simulate the time series of announcement dates, $D_{t}^{E}$, assuming that adverse credit-market news arrive at the jump times of a Poisson process with parameter $l^{E}$. We employ the compensator method described in Duffie and Singleton (2003) to simulate the event times. Similarly to $D_{t}^{E}$, we simulate the time series of $D_{t}^{R}$ according to the jumps times of an independent Poisson process with parameter $l^{R}$. In a second step, we jointly simulate the time series of CDS, options and stock returns. Using the simulated return series, we then compute CDS and IV innovations. (For the purpose of this simulation study, we simplify the definition innovations introduced in Section 2.2.1 to include only one lag and by ignoring the interaction with $\left.D D_{t}\right)$. Finally, we perform three sets of regressions: (6), specification I of (11), and specification I of (13). Our focus is on the information flow from CDS and 
options markets prior to negative credit news, so we replace $\sum_{z \in\{\text { pre,at,post }\}} b^{z} D_{\bullet}^{z, i}(t)$ by $b^{\text {pre }} D_{t+1}^{E}+b^{a t} D_{t}^{E}$. Similarly for $\sum_{z \in\{\text { pre,at,post }\}} c^{z} D_{\bullet}^{z, i}(t)$ and $\sum_{z \in\{\text { pre,at,post }\}} d^{z} D_{\bullet}^{z, i}(t)$.

Results are reported in Table 9. Even though the framework in (15) through (17) is undoubtedly only a simplified version of reality, it is nevertheless rich enough to generate many of the empirical facts summarized in Section 5.3. All twelve model specifications exhibit a positive unconditional flow of information from CDS to options markets and vice versa. There is no significant unconditional information revelation from CDS to equity markets (after accounting for the news revealed in options prices), but a somewhat more significant, although still very small, flow of information from options to equity markets. These findings are in line with the corresponding results in Tables 3 through 7 (specification I).

In model specifications M1, M5 and M9, CDS and options markets receive news regarding adverse credit-market events simultaneously. The corresponding three columns in Table 9 reveal that this implies no conditional positive spillover effects between the two markets and either no conditional negative spillovers from either derivatives market to the equity market (M1), strong negative incremental transmission rates from both derivatives markets to the equity market on the day of the announcement (M5), or strong negative incremental transmission rates from both derivatives markets to the equity market one day before the announcement (M9).

Specifications M2 and M6 show results were the options market trades on news regarding a future announcement one day before the CDS market does, whereas M4 and M8 capture scenarios where the CDS market leads the options market by a day. The results in Table 9 show that for M2 there is a strong conditional spillover from the options market to both the credit and the equity market on the day of the announcement, whereas for M6 the incremental flow of information from options to CDS markets occurs one day prior to the announcement, and then the equity market learns from the CDS market (and not the options market) at the time the news is released. For models M4 and M8, we find a significant conditional transmission of information from the CDS market on the day of the announcement (M4) or one day 
prior to it (M8). In specification M3, the options market leads the CDS market by two days, and vice versa for M7. For the former scenario, the simulation results show no positive (negative) incremental flow of information from options to CDS (equity) markets in response to the options-market news. We also don't find any positive conditional flow from credit to options markets in M7, although we do detect a strong and significant spillover to equity markets prior to the announcement.

The simulation results for our benchmark models M1 through M9 display a wide range of possible lead-lag relationships between credit, options and equity markets. In particular, we find that the information flows around Type $\mathrm{E}$ announcements behave similar in spirit to the predictions of model M4, where the CDS market trades on insider information about news that is bad for the firm's creditors one day prior it being publicly announced. M1 and - to a lesser extent-M3 display a pattern similar to that observed for Type B announcements, in that there are no significant spillover effects from either the CDS or the options market to the equity market prior to or on the day of the news disclosure.

The remaining three models M10, M11 and M12 were specified so as to capture, at least in spirit, the information-flow structure observed for Type A, Type S and Type L announcements, respectively. For M10, information regarding adverse news arrives first in the options market, and only with a one-day delay in the CDS market. The news is publicly announced two days after an upward jump in IV was first observed. To capture the positive conditional spillover effect from options to CDS markets on Type A announcement days, we allow both derivatives markets to adjust to the news in two steps: with a large upward jump in returns that is followed by a second smaller upward jump the next day. Similar considerations lead to specification M11. To mimic the results for news of Type $\mathrm{S}$, the model needs to generate a positive conditional spillover from options to CDS markets prior to the announcement (via $\kappa_{2}^{o, E}>0$ and $\kappa_{1}^{c, E}>0$ ), as well as a negative conditional spillover from CDSinnov ${ }_{e, o}$ to STKrtn also prior to the news release (via $\kappa_{2}^{c, E}>0$ and $\kappa^{e, E}<0$ ).

Finally, M12 is designed to generate a set of results that is similar to our find- 
ings for LBO announcements. Indeed, the model predicts strong positive conditional spillover effects from CDS to options markets and vice versa before the news is publicly

disclosed (via $\kappa_{2}^{c, E}>0$ and $\kappa_{2}^{o, E}>0$ ), a significant positive conditional transmission of information from CDS to equity markets one day before the news breaks, and a significant positive conditional spillover from options to equity markets at the time of the announcement. The latter two effects are achieved by enforcing $\kappa^{e, E}>0$, $\kappa_{2}^{c, E}>\kappa_{2}^{o, E}>0$ and $\kappa_{1}^{o, E}>\kappa_{1}^{c, E}>0$.

\section{Discussion and Conclusion}

In this section, we substantiate our conjecture that the options market trades on unsubstantiated rumors more often than does the default swap market. In particular, we

- analyze the differences in participants in the two derivatives markets, and

- offer empirical evidence that dramatic upward jumps in implied volatilities are revised more frequently and sooner than are dramatic upward jumps in CDS.

We discuss these potential explanations in order.

CDS are typically traded in lots of $\$ 5$ million notional, making them the exclusive domain of large institutional investors. According to Mengle (2007), banks and security firms (59\%) and hedge funds (28\%) accounted for $87 \%$ of the protection buyers in the credit derivatives market in 2006, as a fraction of notional. Banks (44\%), hedge funds (32\%) and insurance companies (17\%) accounted for $93 \%$ of the protection sellers. The remaining activity stemmed from pension funds, mutual funds and corporations.

The breakdown of credit-market participants is different from that of optionsmarket participants, in that a significant share of the latter market is held by small investors. Lakonishok, Lee, Pearson, and Poteshman (2007) report that customers of discount brokers, on average across time, stocks and types of contract, account for 
$12 \%$ of the average daily open interest generated by non-market maker investors for equity options listed at the Chicago Board Options Exchange (CBOE). Customers of full-service brokers account for $71 \%$, with the remaining $17 \%$ of the open interest generated by firm proprietary traders. Similarly, discount customers, full-service customers and firm proprietary traders account for 10\%,75\% and 15\% of the average daily trading volume, respectively. Discount brokers are geared toward smaller, do-ityourself investors. Clients of E-trade are an example of discount customers, whereas clients of Merrill Lynch or Morgan Stanley would be categorized as full-service customers. An example of a firm proprietary trader is an employee of an investment bank who trades for the bank's own account.

These statistics show that the options market has, in sharp contrast to the CDS market, a non-negligible fraction of small investors. In addition, we find that the market share of banks trading on their own books is substantially smaller in the options market than it is in the CDS market. The latter observation is especially important in the context of Acharya and Johnson (2007a), who show that banks that have lending or monitoring relations with a given firm often have nonpublic advance information about negative credit news regarding that firm. Combined, these observations lead us to the conclusion that the fraction of informed investors is higher in the CDS market than it is in the options market, which is consistent with our conjecture that the options market trades on unsubstantiated rumors more than does the CDS market.

A second indication that options are more likely to trade on unsubstantiated rumors is the fact that dramatic upward jumps in implied volatilities are revised more frequently and significantly sooner than are dramatic upward jumps in CDS. During our sample period, more than one third of all dramatic upward jumps in implied volatilities, as defined in (4), were revised downward by $50 \%$ or more of their initial increase within three days. In comparison, less than $18 \%$ of dramatic upward jumps in CDS rates, as defined in (3), were revised downward by $50 \%$ or more within three days of their sudden increase. The average time until a $50 \%$ revision of the 
initial increase in IV amounted to 27 days, with a standard deviation of 1.2 days. For jumps in default swap rates, the average time to a $50 \%$ revision was 49.1 days, with a standard deviation of 2.2 days. The median numbers of days were 7 for IV jumps and 15 for CDS jumps. This evidence is consistent with options trading on unsubstantiated rumors more frequently, creating dramatic spikes in options prices and trading stirs that end in a whimper.

In a theoretical effort to support our conjecture, Section 6 describes a simple model of information arrival and transmission that explicitly incorporates the notion that options markets trade on unsubstantiated rumors more often than do default swap markets. We show that our model, although quite simple, is rich enough to capture the essence of our empirical findings.

In summary, this paper provides empirical evidence that both CDS and options markets often experience abnormal swings prior to the announcement of negative credit news. With the exclusion of negative earnings announcements, we find that options prices reveal information about such forthcoming adverse events at least as early as do credit spreads. Prior to certain adverse credit-market events, notably the disclosure of accounting scandals, we even find that the incremental information revelation in the options market relative to the CDS market is significant.

We observe a strong incremental spillover from CDS to equity markets around adverse earnings releases, and — although with the opposite sign — prior to leveraged buyout announcements, even after controlling for news revealed in options prices. In the period prior to negative credit news being publicly disclosed, we find that the equity market does not respond to abnormal movement in options prices unless that information has also manifested itself in the CDS market. A potential explanation is that options are more likely to trade on unsubstantiated rumors than are default swaps. We propose a theoretical model of information arrival and transmission for credit, options and equity markets that supports our empirical findings. 


\section{Tables}

Table 1: Firm Summary Statistics by Sector. For each of the nine sectors in our sample, we report the number of firms, the average number of daily five-year CDS rate observations per firm, the median CDS rate in basis points, and the distribution of the median S\&P credit rating for the firms in that sector. The sample period is January 2002 through November 2006.

\begin{tabular}{|c|c|c|c|c|c|c|c|c|c|c|c|}
\hline Sector & Firms & No obs & Med CDS & AAA & $\mathrm{AA}$ & $\mathrm{A}$ & $\mathrm{BBB}$ & $\mathrm{BB}$ & $\mathrm{B}$ & $\mathrm{CCC}$ & NR \\
\hline Basic Materials & 10 & 1,115 & 41 & 0 & 0 & 5 & 4 & 0 & 1 & 0 & 0 \\
\hline Consumer Goods & 24 & 1,152 & 51 & 0 & 2 & 5 & 8 & 2 & 5 & 1 & 1 \\
\hline Consumer Services & 14 & 1,001 & 65 & 0 & 0 & 1 & 10 & 0 & 3 & 0 & 0 \\
\hline Healthcare & 20 & 991 & 38 & 1 & 2 & 4 & 10 & 1 & 1 & 0 & 1 \\
\hline Industrials & 18 & 1,169 & 42 & 0 & 1 & 8 & 9 & 0 & 0 & 0 & 0 \\
\hline Oil \& Gas & 21 & 1,117 & 51 & 0 & 0 & 5 & 10 & 4 & 1 & 0 & 1 \\
\hline Technology & 10 & 1,159 & 74 & 0 & 0 & 4 & 1 & 3 & 1 & 0 & 1 \\
\hline Telecommunications & 12 & 863 & 77 & 0 & 0 & 4 & 4 & 2 & 1 & 0 & 1 \\
\hline Utilities & 15 & 1,123 & 54 & 0 & 0 & 0 & 12 & 3 & 0 & 0 & 0 \\
\hline Total sample & 144 & 1,083 & 50 & $1 \%$ & $3 \%$ & $25 \%$ & $47 \%$ & $10 \%$ & $9 \%$ & $1 \%$ & $3 \%$ \\
\hline
\end{tabular}


Table 2: Summary statistics for firms with LBO announcement. For each firm, we report the sector, the LBO announcement date, the number of daily five-year CDS rate observations, the median CDS rate, and the median S\&P credit rating. Datastream CDS data is available from January 2003 through December 2006.

\begin{tabular}{llrrrr}
\hline \hline Firm & sector & anmt date & no. CDS & median CDS & median S\&P rating \\
\hline Albertsons Inc & Consumer Services & $9 / 2 / 05$ & 988 & 80 & BBB \\
Clear Channel Comms Inc & Consumer Services & $10 / 26 / 06$ & 986 & 93 & BBB \\
Equity Office Prop Trust & Consumer Services & $11 / 21 / 06$ & 850 & 44 & BBB \\
Freescale Semiconductor Inc & Technology & $9 / 11 / 06$ & 389 & 86 & BB \\
HCA Inc & Healthcare & $7 / 24 / 06$ & 835 & 140 & BB \\
Kinder Morgan Inc & Oil \& Gas & $5 / 30 / 06$ & 985 & 47 & BBB \\
Neiman Marcus Group Inc & Consumer Services & $3 / 16 / 05$ & 910 & 55 & BBB \\
Toys R Us Inc & Consumer Services & $3 / 16 / 05$ & 816 & 491 & BB \\
Sabre Group Holdings Inc & Consumer Services & $12 / 11 / 06$ & 919 & 75 & BBB \\
Univision Comms Inc & Consumer Services & $6 / 27 / 06$ & 157 & 338 & BB \\
\hline \hline
\end{tabular}


Table 3: Information flow between CDS and options markets under different credit- and options-market conditions. The top panel of the table reports OLS panel estimates and $t$-statistics (in parentheses) for the coefficients of the regression

$$
I \operatorname{Vrtn}_{t}^{i}=a^{i}+\left[b_{t}^{i}+\sum_{z \in\{\mathrm{pre}, \mathrm{at}, \mathrm{post}\}} b^{z} D_{\text {cond }}^{z, i}(t)\right] \operatorname{CDSinnov}_{o}^{i}(t-1)+\left[c_{t}^{i}+\sum_{z \in\{\mathrm{pre}, \mathrm{at}, \mathrm{post}\}} c^{z} D_{\text {cond }}^{z, i}(t)\right] I V r t n_{t-1}^{i}+\epsilon_{t}^{i}
$$

where $b_{t}^{i}=b+b^{\mathrm{DD}}\left[D D_{t}^{i}-\operatorname{avg}_{j, s}\left(D D_{s}^{j}\right)\right]+b^{\mathrm{IV}}\left[\log \left(I V_{t}^{i}\right)-\operatorname{avg}_{j, s}\left(\log \left(I V_{s}^{j}\right)\right)\right]+b^{\mathrm{SZ}}\left[\log \left(S Z_{t}^{i}\right)-\operatorname{avg}_{j, s}\left(\log \left(S Z_{s}^{j}\right)\right)\right]+\sum_{\text {sectors }} b^{s} D^{s, i}+\sum_{\mathrm{qtrs}} b^{q} D_{t}^{q, i}$ and $c_{t}^{i}$ is defined in a similar fashion. Results are reported for four choices of condition dummies $D_{\text {cond }}^{\bullet}$, cond $\in\{\Delta C D S, \Delta I V, \Delta V l m C, \Delta V l m P\}$, and three model specifications (I) $a^{i}=a$, $b_{t}^{i}=b$, and $c_{t}^{i}=c$, (II) $b^{s}=c^{s}=0$ and $b^{q}=c^{q}=0$, and (III) full model, where the latter uses the Basic Materials sector and the first quarter of 2002 as baseline. Note that the entries for $b$ under columns marked III show the sample average of the quarterly dummy estimates and of their $t$-statistics. The bottom panel reports the results of the panel regression above after replacing all instances of IVrtn and CDSinnov ${ }_{o}^{i}$ with CDSrtn and CDSinnov ${ }_{c}^{i}$, respectively.

\begin{tabular}{|c|c|c|c|c|c|c|c|c|c|c|c|c|}
\hline \multirow{2}{*}{$\begin{array}{l}\text { cond. dummy } \\
\text { model spec. }\end{array}$} & \multicolumn{3}{|c|}{$D_{\triangle C D S}^{\bullet}$} & \multicolumn{3}{|c|}{$D_{\Delta I V}^{\bullet}$} & \multicolumn{3}{|c|}{$D_{\Delta V l m C}^{\bullet}$} & \multicolumn{3}{|c|}{$D_{\Delta V l m P}^{\bullet}$} \\
\hline & I & II & III & I & II & III & I & II & III & I & II & III \\
\hline \multirow{3}{*}{$b$} & & & & Inforn & tion flow & om the $\mathrm{CD}$ & market to & he options & narket & & & \\
\hline & 0.049 & 0.050 & 0.041 & 0.024 & 0.024 & 0.024 & 0.045 & 0.035 & 0.038 & 0.045 & 0.034 & 0.037 \\
\hline & $(8.820)$ & (8.959) & (1.532) & $(5.427)$ & $(5.489)$ & $(0.885)$ & (11.165) & (8.657) & (1.406) & (11.215) & $(8.392)$ & (1.398) \\
\hline \multirow[t]{2}{*}{$b^{\text {pre }}$} & 0.013 & -0.008 & -0.008 & -0.023 & -0.035 & -0.024 & 0.045 & 0.036 & 0.029 & 0.043 & 0.046 & 0.040 \\
\hline & $(0.742)$ & $(-0.436)$ & $(-0.475)$ & $(-1.263)$ & $(-1.871)$ & $(-1.292)$ & (1.935) & $(1.572)$ & (1.235) & (1.880) & $(2.037)$ & (1.750) \\
\hline \multirow[t]{2}{*}{$b^{\text {at }}$} & -0.034 & -0.044 & -0.034 & 0.478 & 0.441 & 0.444 & 0.041 & 0.028 & 0.031 & 0.003 & -0.001 & -0.012 \\
\hline & $(-1.250)$ & $(-1.613)$ & $(-1.227)$ & $(22.324)$ & $(20.121)$ & (19.821) & $(1.207)$ & $(0.828)$ & $(0.894)$ & $(0.104)$ & $(-0.017)$ & $(-0.368)$ \\
\hline \multirow[t]{2}{*}{$b^{\text {post }}$} & -0.027 & -0.037 & -0.021 & 0.054 & 0.016 & 0.029 & -0.006 & -0.017 & -0.020 & -0.010 & -0.002 & -0.013 \\
\hline & $(-3.422)$ & $(-4.659)$ & $(-2.381)$ & (5.181) & (1.465) & (2.391) & $(-0.259)$ & $(-0.792)$ & $(-0.930)$ & $(-0.477)$ & $(-0.106)$ & $(-0.603)$ \\
\hline \multirow[t]{2}{*}{$b^{\mathrm{DD}}$} & - & -0.017 & -0.014 & - & -0.023 & -0.022 & - & -0.018 & -0.016 & - & -0.018 & -0.015 \\
\hline & & $(-4.317)$ & $(-3.217)$ & & $(-6.116)$ & $(-5.164)$ & & $(-4.763)$ & $(-3.660)$ & & $(-4.645)$ & $(-3.510)$ \\
\hline \multirow[t]{2}{*}{$b^{\mathrm{IV}}$} & - & 0.037 & 0.055 & - & 0.015 & 0.034 & - & 0.040 & 0.057 & - & 0.041 & 0.060 \\
\hline & & (3.873) & (3.912) & & $(1.560)$ & (2.380) & & $(4.302)$ & $(4.154)$ & & $(4.432)$ & $(4.342)$ \\
\hline$b^{\mathrm{SZ}}$ & - & $\begin{array}{r}0.003 \\
(0.801)\end{array}$ & $\begin{array}{r}0.006 \\
(1.239)\end{array}$ & - & $\begin{array}{r}0.011 \\
(2.823)\end{array}$ & $\begin{array}{r}0.013 \\
(3.065)\end{array}$ & - & $\begin{array}{r}0.008 \\
(1.871)\end{array}$ & $\begin{array}{r}0.010 \\
(2.142)\end{array}$ & - & $\begin{array}{r}0.007 \\
(1.738)\end{array}$ & $\begin{array}{r}0.009 \\
(2.066)\end{array}$ \\
\hline \multicolumn{13}{|c|}{ Information flow from the options market to the CDS market } \\
\hline \multirow[t]{2}{*}{$b$} & 0.016 & 0.026 & 0.023 & 0.021 & 0.034 & 0.033 & 0.033 & 0.044 & 0.037 & 0.032 & 0.042 & 0.036 \\
\hline & (8.333) & $(12.225)$ & (1.773) & $(8.861)$ & (13.647) & $(2.566)$ & (16.774) & (21.170) & $(2.942)$ & (16.091) & $(20.228)$ & (2.837) \\
\hline \multirow[t]{2}{*}{$b^{\text {pre }}$} & 0.046 & 0.024 & 0.016 & 0.007 & 0.041 & 0.023 & -0.005 & -0.017 & -0.017 & 0.030 & 0.028 & 0.023 \\
\hline & $(4.387)$ & (2.309) & $(1.506)$ & $(0.977)$ & (5.933) & (3.120) & $(-0.481)$ & $(-1.561)$ & $(-1.559)$ & (3.073) & $(2.885)$ & $(2.352)$ \\
\hline \multirow[t]{2}{*}{$b^{\text {at }}$} & 0.490 & 0.455 & 0.447 & 0.035 & 0.023 & 0.017 & 0.000 & -0.007 & -0.004 & -0.007 & 0.021 & 0.013 \\
\hline & (32.657) & (29.947) & $(29.384)$ & $(2.865)$ & (1.918) & (1.446) & $(0.014)$ & $(-0.379)$ & $(-0.209)$ & $(-0.462)$ & (1.439) & $(0.871)$ \\
\hline \multirow[t]{2}{*}{$b^{\text {post }}$} & 0.144 & 0.108 & 0.102 & 0.037 & 0.019 & 0.010 & 0.000 & -0.006 & -0.003 & -0.010 & -0.016 & -0.014 \\
\hline & (16.639) & (12.099) & $(11.261)$ & (8.324) & $(4.355)$ & (2.186) & $(-0.022)$ & $(-0.594)$ & $(-0.260)$ & $(-1.009)$ & $(-1.617)$ & $(-1.424)$ \\
\hline \multirow[t]{2}{*}{$b^{\mathrm{DD}}$} & - & 0.003 & 0.002 & - & 0.005 & 0.003 & - & 0.006 & 0.003 & - & 0.006 & 0.004 \\
\hline & & (1.883) & $(0.953)$ & & (3.129) & $(1.800)$ & & $(3.432)$ & (1.730) & & $(3.690)$ & (1.901) \\
\hline \multirow[t]{2}{*}{$b^{\mathrm{IV}}$} & - & 0.048 & 0.047 & - & 0.076 & 0.076 & - & 0.074 & 0.074 & - & 0.074 & 0.074 \\
\hline & & (12.332) & $(9.360)$ & & $(19.452)$ & $(14.859)$ & & (19.792) & (14.973) & & (19.810) & (14.977) \\
\hline \multirow[t]{2}{*}{$b^{\mathrm{SZ}}$} & - & -0.002 & -0.001 & - & -0.005 & -0.003 & - & -0.006 & -0.003 & - & -0.007 & -0.003 \\
\hline & & $(-0.890)$ & $(-0.379)$ & & $(-2.351)$ & $(-1.332)$ & & $(-3.043)$ & $(-1.420)$ & & $(-3.307)$ & $(-1.554)$ \\
\hline
\end{tabular}


Table 4: Information flow between the CDS and options markets by announcement type. The top panel of the table reports OLS panel estimates and $t$-statistics (in parentheses) for the coefficients of the regression

$$
I V r t n_{t}^{i}=a^{i}+\left[b_{t}^{i}+\sum_{z \in\{\text { pre,at }, \text { post }\}} b^{z} D_{\text {anmt }}^{z, i}(t)\right] \operatorname{CDSinnov}_{o}^{i}(t-1)+\left[c_{t}^{i}+\sum_{z \in\{\text { pre }, \mathrm{at}, \mathrm{post}\}} c^{z} D_{\text {anmt }}^{z, i}(t)\right] I V r t n_{t-1}^{i}+\epsilon_{t}^{i},
$$

where $b_{t}^{i}=b+b^{\mathrm{DD}}\left[D D_{t}^{i}-\operatorname{avg}_{j, s}\left(D D_{s}^{j}\right)\right]+b^{\mathrm{IV}}\left[\log \left(I V_{t}^{i}\right)-\operatorname{avg}_{j, s}\left(\log \left(I V_{s}^{j}\right)\right)\right]+b^{\mathrm{SZ}}\left[\log \left(S Z_{t}^{i}\right)-\operatorname{avg}_{j, s}\left(\log \left(S Z_{s}^{j}\right)\right)\right]+\sum_{\text {sectors }} b^{s} D^{s, i}+\sum_{\mathrm{qtrs}} b^{q} D_{t}^{q, i}$ and $c_{t}^{i}$ is defined in a similar fashion. Results are reported for four announcement types (A, E, S, and B) and three model specifications (I) $a^{i}=a, b_{t}^{i}=b$, and $c_{t}^{i}=c,(\mathrm{II}) b^{s}=c^{s}=0$ and $b^{q}=c^{q}=0$, and (III) full model, where the latter uses the Basic Materials sector and the first quarter of 2002 as baseline. Note that the entries for $b$ under columns marked III show the sample average of the quarterly dummy estimates and of their $t$-statistics. The bottom panel reports the results of the panel regression above after replacing all instances of IVrtn and CDSinnov $v_{o}^{i}$ with CDSrtn and CDSinnov $v_{c}^{i}$, respectively.

\begin{tabular}{|c|c|c|c|c|c|c|c|c|c|c|c|c|}
\hline \multirow{2}{*}{$\begin{array}{l}\text { cond. dummy } \\
\text { model spec. }\end{array}$} & \multicolumn{3}{|c|}{ A } & \multicolumn{3}{|c|}{$\mathrm{E}$} & \multicolumn{3}{|c|}{$\mathrm{S}$} & \multicolumn{3}{|c|}{ B } \\
\hline & I & II & III & I & II & III & I & II & III & I & II & III \\
\hline \multirow{3}{*}{$b$} & & & & Inforn & ation flow & om the CD & market to & the options & market & & & \\
\hline & 0.044 & 0.035 & 0.038 & 0.041 & 0.034 & 0.036 & 0.045 & 0.035 & 0.038 & 0.045 & 0.035 & 0.036 \\
\hline & (11.239) & $(8.937)$ & (1.418) & $(10.447)$ & $(8.441)$ & $(1.362)$ & (11.735) & (8.993) & (1.439) & (11.638) & $(8.879)$ & $(1.357)$ \\
\hline \multirow[t]{2}{*}{$b^{\text {pre }}$} & -0.131 & -0.162 & -0.161 & 0.005 & -0.031 & -0.039 & -0.018 & -0.054 & -0.073 & 0.037 & 0.027 & 0.008 \\
\hline & $(-1.570)$ & $(-1.935)$ & $(-1.929)$ & $(0.143)$ & $(-0.845)$ & $(-1.050)$ & $(-0.253)$ & $(-0.756)$ & $(-1.010)$ & $(0.551)$ & $(0.400)$ & $(0.118)$ \\
\hline \multirow[t]{2}{*}{$b^{\text {at }}$} & 0.041 & -0.012 & -0.074 & 0.208 & 0.163 & 0.169 & 0.207 & 0.154 & 0.104 & 0.018 & 0.047 & 0.032 \\
\hline & $(0.669)$ & $(-0.200)$ & $(-1.183)$ & (3.933) & $(3.074)$ & $(3.183)$ & $(3.568)$ & $(2.646)$ & $(1.741)$ & $(0.291)$ & $(0.776)$ & $(0.520)$ \\
\hline \multirow[t]{2}{*}{$b^{\text {post }}$} & 0.076 & 0.002 & 0.018 & 0.107 & 0.057 & 0.042 & -0.147 & -0.178 & -0.196 & 0.051 & 0.014 & 0.015 \\
\hline & (1.644) & $(0.051)$ & $(0.374)$ & $(4.542)$ & $(2.344)$ & (1.696) & $(-1.946)$ & $(-2.356)$ & $(-2.585)$ & (1.186) & $(0.321)$ & $(0.340)$ \\
\hline \multirow[t]{2}{*}{$b^{\mathrm{DD}}$} & - & -0.018 & -0.016 & - & -0.017 & -0.015 & - & -0.018 & -0.016 & - & -0.018 & -0.016 \\
\hline & & $(-4.675)$ & $(-3.661)$ & & $(-4.400)$ & $(-3.414)$ & & $(-4.601)$ & $(-3.582)$ & & $(-4.682)$ & $(-3.558)$ \\
\hline \multirow[t]{2}{*}{$b^{\mathrm{IV}}$} & - & 0.040 & 0.056 & - & 0.037 & 0.056 & - & 0.042 & 0.060 & - & 0.042 & 0.059 \\
\hline & & $(4.211)$ & $(3.987)$ & & (3.932) & $(4.034)$ & & $(4.465)$ & $(4.342)$ & & $(4.441)$ & $(4.307)$ \\
\hline \multirow[t]{3}{*}{$b^{\mathrm{SZ}}$} & - & 0.008 & 0.010 & - & 0.006 & 0.008 & - & 0.008 & 0.010 & - & 0.007 & 0.009 \\
\hline & & $(1.860)$ & $(2.162)$ & & (1.416) & $(1.814)$ & & $(1.877)$ & $(2.247)$ & & (1.811) & $(2.092)$ \\
\hline & \multicolumn{12}{|c|}{ Information flow from the options market to the CDS market } \\
\hline \multirow[t]{2}{*}{$b$} & 0.029 & 0.040 & 0.035 & 0.032 & 0.043 & 0.036 & 0.033 & 0.043 & 0.036 & 0.033 & 0.043 & 0.036 \\
\hline & $(15.457)$ & (19.825) & $(2.785)$ & (16.701) & $(21.210)$ & (2.894) & $(17.252)$ & $(21.501)$ & $(2.888)$ & (17.137) & (21.369) & (2.873) \\
\hline \multirow[t]{2}{*}{$b^{\text {pre }}$} & 0.164 & 0.138 & 0.153 & 0.045 & 0.022 & 0.018 & 0.122 & 0.110 & 0.116 & 0.033 & 0.036 & 0.053 \\
\hline & $(4.145)$ & $(3.484)$ & $(3.889)$ & $(2.294)$ & (1.100) & $(0.903)$ & $(3.287)$ & $(2.976)$ & (3.144) & $(0.959)$ & (1.032) & $(1.536)$ \\
\hline \multirow[t]{2}{*}{$b^{\text {at }}$} & 0.493 & 0.412 & 0.408 & 0.018 & -0.010 & -0.013 & -0.119 & -0.148 & -0.117 & 0.085 & 0.080 & 0.080 \\
\hline & (17.795) & (14.709) & $(14.345)$ & $(0.767)$ & $(-0.412)$ & $(-0.564)$ & $(-1.920)$ & $(-2.399)$ & $(-1.898)$ & $(1.714)$ & (1.620) & $(1.623)$ \\
\hline \multirow[t]{2}{*}{$b^{\text {post }}$} & 0.093 & 0.051 & 0.054 & 0.010 & -0.014 & -0.018 & -0.022 & -0.036 & -0.034 & -0.050 & -0.058 & -0.035 \\
\hline & $(3.177)$ & (1.747) & $(1.853)$ & $(0.547)$ & $(-0.741)$ & $(-0.976)$ & $(-0.634)$ & $(-1.053)$ & $(-0.987)$ & $(-1.407)$ & $(-1.626)$ & $(-0.993)$ \\
\hline$b^{\mathrm{DD}}$ & - & 0.007 & 0.004 & - & $\begin{array}{r}0.006 \\
(3.474)\end{array}$ & 0.003 & - & $\begin{array}{r}0.006 \\
(3.429)\end{array}$ & 0.003 & - & 0.006 & $\begin{array}{r}0.003 \\
(1749)\end{array}$ \\
\hline \multirow{2}{*}{$b^{\mathrm{IV}}$} & - & $\begin{array}{r}(3.934) \\
0.067\end{array}$ & $\begin{array}{r}(1.994) \\
0.061\end{array}$ & - & $\begin{array}{r}(3.474) \\
0.073\end{array}$ & $\begin{array}{r}(1.770) \\
0.074\end{array}$ & - & $\begin{array}{r}(3.429) \\
0.074\end{array}$ & $\begin{array}{r}(1.751) \\
0.074\end{array}$ & - & $\begin{array}{r}(3.446) \\
0.073\end{array}$ & $\begin{array}{r}(1.749) \\
0.073\end{array}$ \\
\hline & & (17.949) & $(12.230)$ & & $(19.669)$ & (14.919) & & $(19.789)$ & $(14.974)$ & & $(19.673)$ & (14.888) \\
\hline$b^{\mathrm{SZ}}$ & - & -0.005 & -0.003 & - & -0.006 & -0.003 & - & -0.006 & -0.003 & - & -0.006 & -0.003 \\
\hline & & $(-2.368)$ & $(-1.228)$ & & $(-3.124)$ & $(-1.471)$ & & $(-3.136)$ & $(-1.499)$ & & $(-3.111)$ & $(-1.497)$ \\
\hline
\end{tabular}


Table 5: Information flow from CDS and options markets to the equity market under different credit- and options-market conditions. This table reports OLS panel estimates and $t$-statistics (in parentheses) for the coefficients of the regression

$$
\operatorname{STKrtn}_{t}^{i}=a^{i}+\left[b_{t}^{i}+\sum_{z \in\{\mathrm{pre}, \mathrm{at}, \mathrm{post}\}} b^{z} D_{\text {cond }}^{z, i}(t)\right] \operatorname{CDSinnov}_{e, o}^{i}(t-1)+\left[d_{t}^{i}+\sum_{z} d^{z} D_{\text {cond }}^{z, i}(t)\right] \operatorname{IVinnov}_{e}^{i}(t-1)+\left[c_{t}^{i}+\sum_{z} c^{z} D_{\text {cond }}^{z, i}(t)\right] S T K r t n_{t-1}^{i}+\epsilon_{t}^{i},
$$

where $b_{t}^{i}=b+b^{\mathrm{DD}}\left[D D_{t}^{i}-\operatorname{avg}_{j, s}\left(D D_{s}^{j}\right)\right]+b^{\mathrm{IV}}\left[\log \left(I V_{t}^{i}\right)-\operatorname{avg}_{j, s}\left(\log \left(I V_{s}^{j}\right)\right)\right]+b^{\mathrm{SZ}}\left[\log \left(S Z_{t}^{i}\right)-\operatorname{avg}_{j, s}\left(\log \left(S Z_{s}^{j}\right)\right)\right]+\sum_{\text {sectors }} b^{s} D^{s, i}+\sum_{\mathrm{qtrs}} b^{q} D_{t}^{q, i}$ and $c_{t}^{i}$ and $d_{t}^{i}$ are defined in a similar fashion. Results are reported for four choices of condition dummies $D_{\text {cond }}^{\bullet}$, cond $\in\{\Delta C D S, \Delta I V, \Delta V l m C, \Delta V l m P\}$, and three model specifications (I) $a^{i}=a, b_{t}^{i}=b, d_{t}^{i}=d$, and $c_{t}^{i}=c$, (II) $b^{s}=d^{s}=c^{s}=0$ and $b^{q}=d^{q}=c^{q}=0$, and (III) full model, where the latter uses the Basic Materials sector and the first quarter of 2002 as baseline. Note that the entries for $b$ and $d$ under columns marked III show the sample average of the quarterly dummy estimates and of their $t$-statistics.

\begin{tabular}{|c|c|c|c|c|c|c|c|c|c|c|c|c|}
\hline & \multicolumn{3}{|c|}{$D_{\triangle C D S}^{\bullet}$} & \multicolumn{3}{|c|}{$D_{\Delta I V}^{\bullet}$} & \multicolumn{3}{|c|}{$D_{\Delta V l m C}^{\bullet}$} & \multicolumn{3}{|c|}{$D_{\Delta V l m P}^{\bullet}$} \\
\hline & I & II & III & I & II & III & I & II & III & I & II & III \\
\hline$b$ & $\begin{array}{r}-0.004 \\
(-1.979)\end{array}$ & $\begin{array}{r}-0.004 \\
(-1.734)\end{array}$ & $\begin{array}{r}-0.005 \\
(-0.385)\end{array}$ & $\begin{array}{r}0.000 \\
(0.123)\end{array}$ & $\begin{array}{r}0.000 \\
(0.089)\end{array}$ & $\begin{array}{r}-0.001 \\
(-0.021)\end{array}$ & $\begin{array}{r}-0.007 \\
(-4.056)\end{array}$ & $\begin{array}{r}-0.005 \\
(-2.594)\end{array}$ & $\begin{array}{r}-0.007 \\
(-0.559)\end{array}$ & $\begin{array}{r}-0.008 \\
(-4.763)\end{array}$ & $\begin{array}{r}-0.006 \\
(-3.146)\end{array}$ & $\begin{array}{r}-0.007 \\
(-0.637)\end{array}$ \\
\hline$b^{\text {pre }}$ & -0.006 & -0.001 & 0.000 & -0.001 & 0.001 & -0.002 & -0.006 & -0.003 & -0.003 & 0.021 & 0.022 & 0.023 \\
\hline & & $(-0.109)$ & $(-0.007)$ & $(-0.142)$ & $(0.170)$ & $(-0.209)$ & $(-0.643)$ & $(-0.342)$ & $(-0.281)$ & (2.183) & (2.318) & $(2.420)$ \\
\hline$b^{\mathrm{a}}$ & $\begin{array}{r}-0.028 \\
(-2.454)\end{array}$ & $\begin{array}{r}-0.026 \\
(-2.308)\end{array}$ & $\begin{array}{r}-0.032 \\
(-2.784)\end{array}$ & $\begin{array}{r}-0.102 \\
(-10.992)\end{array}$ & $\begin{array}{r}-0.097 \\
(-10.284)\end{array}$ & $\begin{array}{r}-0.097 \\
(-10.067)\end{array}$ & $\begin{array}{r}-0.013 \\
(-0.901)\end{array}$ & $\begin{array}{r}-0.009 \\
(-0.624)\end{array}$ & $\begin{array}{r}-0.015 \\
(-1.091)\end{array}$ & $\begin{array}{r}-0.010 \\
(-0.717)\end{array}$ & $\begin{array}{r}-0.007 \\
(-0.516)\end{array}$ & $\begin{array}{r}-0.002 \\
(-0.141)\end{array}$ \\
\hline$b^{\text {post }}$ & $\begin{array}{r}-0.002 \\
(-0.690)\end{array}$ & $\begin{array}{r}-0.001 \\
(-0.294)\end{array}$ & $\begin{array}{r}-0.003 \\
(-0.730)\end{array}$ & $\begin{array}{r}-0.030 \\
(-6.224)\end{array}$ & $\begin{array}{r}-0.025 \\
(-4.951)\end{array}$ & $\begin{array}{r}-0.024 \\
(-4.538)\end{array}$ & $\begin{array}{r}-0.023 \\
(-2.589)\end{array}$ & $\begin{array}{r}-0.021 \\
(-2.283)\end{array}$ & $\begin{array}{r}-0.024 \\
(-2.631)\end{array}$ & $\begin{array}{r}-0.010 \\
(-1.153)\end{array}$ & $\begin{array}{r}-0.012 \\
(-1.376)\end{array}$ & $\begin{array}{r}-0.010 \\
(-1.155)\end{array}$ \\
\hline$b^{\mathrm{DD}}$ & - & $\begin{array}{r}0.007 \\
(4.068)\end{array}$ & $\begin{array}{r}0.003 \\
(1.702)\end{array}$ & - & $\begin{array}{r}0.008 \\
(4.882)\end{array}$ & $\begin{array}{r}0.004 \\
(2.245)\end{array}$ & - & $\begin{array}{r}0.006 \\
(3.870)\end{array}$ & $\begin{array}{r}0.003 \\
(1.418)\end{array}$ & - & $\begin{array}{r}0.006 \\
(3.994)\end{array}$ & $\begin{array}{r}0.003 \\
(1.601)\end{array}$ \\
\hline$b^{\mathrm{IV}}$ & - & $\begin{array}{r}-0.015 \\
(-3.423)\end{array}$ & $\begin{array}{r}-0.029 \\
(-4.682)\end{array}$ & - & $\begin{array}{r}-0.004 \\
(-0.838)\end{array}$ & $\begin{array}{r}-0.020 \\
(-3.254)\end{array}$ & - & $\begin{array}{r}-0.017 \\
(-4.016)\end{array}$ & $\begin{array}{r}-0.031 \\
(-5.205)\end{array}$ & - & $\begin{array}{r}-0.017 \\
(-3.979)\end{array}$ & $\begin{array}{r}-0.031 \\
(-5.082)\end{array}$ \\
\hline$b^{\mathrm{SZ}}$ & - & $\begin{array}{r}-0.006 \\
(-3.522)\end{array}$ & $\begin{array}{r}-0.005 \\
(-2.807)\end{array}$ & - & $\begin{array}{r}-0.005 \\
(-2.944)\end{array}$ & $\begin{array}{r}-0.004 \\
(-2.331)\end{array}$ & - & $\begin{array}{r}-0.006 \\
(-3.634)\end{array}$ & $\begin{array}{r}-0.005 \\
(-2.890)\end{array}$ & - & $\begin{array}{r}-0.006 \\
(-3.712)\end{array}$ & $\begin{array}{r}-0.006 \\
(-2.970)\end{array}$ \\
\hline$d$ & $\begin{array}{r}-0.005 \\
(-4.236)\end{array}$ & $\begin{array}{r}-0.007 \\
(-5.429)\end{array}$ & $\begin{array}{r}-0.001 \\
(-0.173)\end{array}$ & $\begin{array}{r}-0.007 \\
(-4.708)\end{array}$ & $\begin{array}{r}-0.010 \\
(-6.595)\end{array}$ & $\begin{array}{r}-0.004 \\
(-0.551)\end{array}$ & $\begin{array}{r}-0.007 \\
(-6.101)\end{array}$ & $\begin{array}{r}-0.009 \\
(-6.838)\end{array}$ & $\begin{array}{r}-0.002 \\
(-0.292)\end{array}$ & $\begin{array}{r}-0.008 \\
(-6.933)\end{array}$ & $\begin{array}{r}-0.010 \\
(-7.553)\end{array}$ & $\begin{array}{r}-0.003 \\
(-0.432)\end{array}$ \\
\hline$d^{\text {pre }}$ & $\begin{array}{r}-0.006 \\
(-0.886)\end{array}$ & $\begin{array}{r}0.000 \\
(-0.041)\end{array}$ & $\begin{array}{r}-0.002 \\
(-0.303)\end{array}$ & $\begin{array}{r}-0.008 \\
(-2.019)\end{array}$ & $\begin{array}{r}-0.015 \\
(-3.599)\end{array}$ & $\begin{array}{r}-0.018 \\
(-4.089)\end{array}$ & $\begin{array}{r}-0.006 \\
(-0.963)\end{array}$ & $\begin{array}{r}-0.005 \\
(-0.740)\end{array}$ & $\begin{array}{r}-0.005 \\
(-0.689)\end{array}$ & $\begin{array}{r}0.005 \\
(0.920)\end{array}$ & $\begin{array}{r}0.005 \\
(0.813)\end{array}$ & $\begin{array}{r}0.005 \\
(0.859)\end{array}$ \\
\hline$d^{\text {at }}$ & $\begin{array}{r}-0.055 \\
(-5.423)\end{array}$ & $\begin{array}{r}-0.044 \\
(-4.231)\end{array}$ & $\begin{array}{r}-0.043 \\
(-4.118)\end{array}$ & $\begin{array}{r}0.046 \\
(6.477)\end{array}$ & $\begin{array}{r}0.049 \\
(6.832)\end{array}$ & $\begin{array}{r}0.050 \\
(6.903)\end{array}$ & $\begin{array}{r}-0.028 \\
(-2.522)\end{array}$ & $\begin{array}{r}-0.028 \\
(-2.435)\end{array}$ & $\begin{array}{r}-0.029 \\
(-2.569)\end{array}$ & $\begin{array}{r}0.000 \\
(-0.030)\end{array}$ & $\begin{array}{r}-0.007 \\
(-0.732)\end{array}$ & $\begin{array}{r}-0.005 \\
(-0.511)\end{array}$ \\
\hline$d^{\mathrm{po}}$ & $\begin{array}{r}-0.031 \\
(-5.912)\end{array}$ & $\begin{array}{r}-0.020 \\
(-3.616)\end{array}$ & $\begin{array}{r}-0.018 \\
(-3.187)\end{array}$ & $\begin{array}{r}-0.005 \\
(-1.973)\end{array}$ & $\begin{array}{r}-0.001 \\
(-0.502)\end{array}$ & $\begin{array}{r}-0.001 \\
(-0.234)\end{array}$ & $\begin{array}{r}-0.008 \\
(-1.184)\end{array}$ & $\begin{array}{r}-0.008 \\
(-1.232)\end{array}$ & $\begin{array}{r}-0.008 \\
(-1.267)\end{array}$ & $\begin{array}{r}0.005 \\
(0.855)\end{array}$ & $\begin{array}{r}0.005 \\
(0.830)\end{array}$ & $\begin{array}{r}0.001 \\
(0.194)\end{array}$ \\
\hline$d^{\mathrm{DD}}$ & - & $\begin{array}{r}0.000 \\
(0.270)\end{array}$ & $\begin{array}{r}0.000 \\
(0.356)\end{array}$ & - & $\begin{array}{r}-0.001 \\
(-0.545)\end{array}$ & $\begin{array}{r}-0.001 \\
(-0.450)\end{array}$ & - & $\begin{array}{r}0.000 \\
(-0.014)\end{array}$ & $\begin{array}{r}0.000 \\
(0.186)\end{array}$ & - & $\begin{array}{r}0.000 \\
(-0.034)\end{array}$ & $\begin{array}{r}0.000 \\
(0.181)\end{array}$ \\
\hline$d^{\mathrm{IV}}$ & - & $\begin{array}{r}-0.010 \\
(-4.159)\end{array}$ & $\begin{array}{r}-0.014 \\
(-4.496)\end{array}$ & - & $\begin{array}{r}-0.017 \\
(-6.974)\end{array}$ & $\begin{array}{r}-0.021 \\
(-6.763)\end{array}$ & - & $\begin{array}{r}-0.013 \\
(-5.709)\end{array}$ & $\begin{array}{r}-0.017 \\
(-5.763)\end{array}$ & - & $\begin{array}{r}-0.013 \\
(-5.846)\end{array}$ & $\begin{array}{r}-0.018 \\
(-5.816)\end{array}$ \\
\hline$d^{\mathrm{SZ}}$ & - & $\begin{array}{r}0.004 \\
(3.470)\end{array}$ & $\begin{array}{r}0.003 \\
(1.880)\end{array}$ & - & $\begin{array}{r}0.005 \\
(3.940)\end{array}$ & $\begin{array}{r}0.003 \\
(2.118)\end{array}$ & - & $\begin{array}{r}0.005 \\
(4.098)\end{array}$ & $\begin{array}{r}0.003 \\
(2.272)\end{array}$ & - & $\begin{array}{r}0.005 \\
(3.926)\end{array}$ & $\begin{array}{r}0.003 \\
(2.120)\end{array}$ \\
\hline
\end{tabular}


Table 6: Information flow from CDS and options markets to the equity market by announcement type. This table reports OLS panel estimates and $t$-statistics (in parentheses) for the coefficients of the regression

$$
S T K r t n_{t}^{i}=a^{i}+\left[b_{t}^{i}+\sum_{z \in\{\text { pre, at }, \text { post }\}} b^{z} D_{\text {anmt }}^{z, i}(t)\right] \operatorname{CDSinnov~}_{e, o}^{i}(t-1)+\left[d_{t}^{i}+\sum_{z} d^{z} D_{\text {anmt }}^{z, i}(t)\right] \operatorname{IVinnov}_{e}^{i}(t-1)+\left[c_{t}^{i}+\sum_{z} c^{z} D_{\text {anmt }}^{z, i}(t)\right] S T K r t n_{t-1}^{i}+\epsilon_{t}^{i},
$$

where $b_{t}^{i}=b+b^{\mathrm{DD}}\left[D D_{t}^{i}-\operatorname{avg}_{j, s}\left(D D_{s}^{j}\right)\right]+b^{\mathrm{IV}}\left[\log \left(I V_{t}^{i}\right)-\operatorname{avg}_{j, s}\left(\log \left(I V_{s}^{j}\right)\right)\right]+b^{\mathrm{SZ}}\left[\log \left(S Z_{t}^{i}\right)-\operatorname{avg} j, s\left(\log \left(S Z_{s}^{j}\right)\right)\right]+\sum_{\text {sectors }} b^{s} D^{s, i}+\sum_{\mathrm{qtrs}} b^{q} D_{t}^{q, i}$ and $c_{t}^{i}$ and $d_{t}^{i}$ are defined in a similar fashion. Results are reported for four announcement types (A, E, S, and B) and three model specifications (I) $a^{i}=a, b_{t}^{i}=b, d_{t}^{i}=d$, and $c_{t}^{i}=c$, (II) $b^{s}=d^{s}=c^{s}=0$ and $b^{q}=d^{q}=c^{q}=0$, and (III) full model, where the latter uses the Basic Materials sector and the first quarter of 2002 as baseline. Note that the entries for $b$ and $d$ under columns marked III show the sample average of the quarterly dummy estimates and of their $t$-statistics.

\begin{tabular}{|c|c|c|c|c|c|c|c|c|c|c|c|c|}
\hline & \multicolumn{3}{|c|}{ A } & \multicolumn{3}{|c|}{$\mathrm{E}$} & \multicolumn{3}{|c|}{ S } & \multicolumn{3}{|c|}{ B } \\
\hline & I & II & III & I & II & III & I & II & III & I & II & III \\
\hline$b$ & $\begin{array}{r}-0.007 \\
(-4.418)\end{array}$ & $\begin{array}{r}-0.005 \\
(-3.051)\end{array}$ & $\begin{array}{r}-0.007 \\
(-0.627)\end{array}$ & $\begin{array}{r}-0.006 \\
(-3.448)\end{array}$ & $\begin{array}{r}-0.004 \\
(-2375)\end{array}$ & $\begin{array}{r}-0.006 \\
(-0.509)\end{array}$ & $\begin{array}{r}-0.007 \\
(-4.362)\end{array}$ & $\begin{array}{r}-0.005 \\
(-2812)\end{array}$ & $\begin{array}{r}-0.007 \\
(-0.592)\end{array}$ & $\begin{array}{r}-0.008 \\
(-4631)\end{array}$ & $\begin{array}{r}-0.005 \\
(-2.975)\end{array}$ & $\begin{array}{r}-0.007 \\
(-0.610)\end{array}$ \\
\hline \multirow[t]{2}{*}{$b^{\text {pre }}$} & 0.122 & 0.137 & 0.138 & -0.046 & -0.035 & -0.029 & -0.094 & -0.078 & -0.073 & -0.001 & 0.008 & 0.017 \\
\hline & (3.407) & (3.817) & (3.832) & $(-2.961)$ & $(-2.222)$ & $(-1.835)$ & $(-3.052)$ & $(-2.523)$ & $(-2.367)$ & $(-0.030)$ & $(0.284)$ & $(0.587)$ \\
\hline \multirow[t]{2}{*}{$b^{\text {at }}$} & -0.107 & -0.099 & -0.095 & -0.128 & -0.111 & -0.113 & -0.013 & 0.005 & 0.013 & 0.032 & 0.021 & 0.025 \\
\hline & $(-3.849)$ & $(-3.532)$ & $(-3.321)$ & $(-5.619)$ & $(-4.846)$ & $(-4.928)$ & $(-0.434)$ & $(0.171)$ & $(0.444)$ & (1.201) & (0.791) & $(0.923)$ \\
\hline \multirow[t]{2}{*}{$b^{\text {post }}$} & -0.066 & -0.042 & -0.034 & -0.038 & -0.024 & -0.019 & -0.016 & -0.006 & -0.008 & -0.080 & -0.072 & -0.072 \\
\hline & $(-3.175)$ & $(-1.995)$ & $(-1.613)$ & $(-3.409)$ & $(-2.075)$ & $(-1.664)$ & $(-0.487)$ & $(-0.199)$ & $(-0.247)$ & $(-4.017)$ & $(-3.649)$ & $(-3.599)$ \\
\hline$b^{\mathrm{DD}}$ & - & $\begin{array}{r}0.006 \\
(3.857)\end{array}$ & $\begin{array}{r}0.003 \\
(1.609)\end{array}$ & - & $\begin{array}{r}0.006 \\
(3.455)\end{array}$ & $\begin{array}{r}0.002 \\
(1.175)\end{array}$ & - & $\begin{array}{r}0.006 \\
(3.450)\end{array}$ & $\begin{array}{r}0.002 \\
(1.340)\end{array}$ & - & $\begin{array}{r}0.006 \\
(4.015)\end{array}$ & $\begin{array}{r}0.003 \\
(1.661)\end{array}$ \\
\hline \multirow[t]{2}{*}{$b^{\mathrm{IV}}$} & - & -0.016 & -0.030 & - & -0.015 & -0.029 & - & -0.016 & -0.030 & - & -0.017 & -0.030 \\
\hline & & $(-3.873)$ & $(-4.893)$ & & $(-3.475)$ & $(-4.779)$ & & $(-3.942)$ & $(-4.926)$ & & $(-4.033)$ & $(-4.970)$ \\
\hline$b^{\mathrm{SZ}}$ & - & $\begin{array}{r}-0.006 \\
(-3.769)\end{array}$ & $\begin{array}{r}-0.006 \\
(-3.077)\end{array}$ & - & $\begin{array}{r}-0.005 \\
(-3.057)\end{array}$ & $\begin{array}{r}-0.005 \\
(-2.437)\end{array}$ & - & $\begin{array}{r}-0.006 \\
(-3.338)\end{array}$ & $\begin{array}{r}-0.005 \\
(-2.763)\end{array}$ & - & $\begin{array}{r}-0.006 \\
(-3.667)\end{array}$ & $\begin{array}{r}-0.005 \\
(-2.847)\end{array}$ \\
\hline \multirow[t]{2}{*}{$d$} & -0.007 & -0.009 & -0.003 & -0.008 & -0.009 & -0.003 & -0.008 & -0.010 & -0.003 & -0.008 & -0.010 & -0.003 \\
\hline & $(-6.490)$ & $(-7.439)$ & $(-0.411)$ & $(-6.571)$ & $(-7.428)$ & $(-0.452)$ & $(-7.128)$ & $(-7.883)$ & $(-0.400)$ & $(-6.952)$ & $(-7.638)$ & $(-0.420)$ \\
\hline \multirow[t]{2}{*}{$d^{\text {pre }}$} & -0.012 & -0.004 & -0.009 & -0.006 & -0.001 & -0.001 & -0.020 & -0.020 & -0.020 & 0.018 & 0.014 & 0.010 \\
\hline & $(-0.435)$ & $(-0.137)$ & $(-0.314)$ & $(-0.485)$ & $(-0.065)$ & $(-0.042)$ & $(-0.865)$ & $(-0.900)$ & $(-0.864)$ & $(0.842)$ & (0.678) & $(0.488)$ \\
\hline \multirow[t]{2}{*}{$d^{\text {at }}$} & -0.047 & -0.023 & 0.003 & 0.010 & 0.018 & 0.022 & 0.088 & 0.092 & 0.098 & 0.005 & 0.003 & -0.001 \\
\hline & $(-1.972)$ & $(-0.954)$ & $(0.126)$ & $(0.673)$ & (1.206) & (1.448) & (2.301) & $(2.400)$ & $(2.544)$ & $(0.173)$ & (0.114) & $(-0.036)$ \\
\hline \multirow[t]{2}{*}{$d^{\text {post }}$} & 0.002 & 0.013 & 0.005 & -0.025 & -0.020 & -0.020 & -0.023 & -0.024 & -0.024 & 0.001 & -0.003 & -0.004 \\
\hline & $(0.091)$ & $(0.693)$ & $(0.277)$ & $(-2.140)$ & $(-1.737)$ & $(-1.726)$ & $(-1.112)$ & $(-1.117)$ & $(-1.157)$ & $(0.044)$ & $(-0.150)$ & $(-0.184)$ \\
\hline \multirow[t]{2}{*}{$d^{\mathrm{DD}}$} & - & 0.000 & 0.000 & - & 0.000 & 0.000 & - & 0.000 & 0.000 & - & 0.000 & 0.000 \\
\hline & & $(-0.076)$ & (0.191) & & $(-0.074)$ & $(0.176)$ & & $(0.013)$ & $(0.183)$ & & $(0.052)$ & $(0.261)$ \\
\hline \multirow[t]{2}{*}{$d^{\mathrm{IV}}$} & - & -0.013 & -0.018 & - & -0.013 & -0.017 & - & -0.014 & -0.019 & - & -0.013 & -0.017 \\
\hline & & $(-5.601)$ & $(-5.786)$ & & $(-5.674)$ & $(-5.745)$ & & $(-6.114)$ & $(-6.172)$ & & $(-5.799)$ & $(-5.811)$ \\
\hline \multirow[t]{2}{*}{$d^{\mathrm{SZ}}$} & - & 0.005 & 0.003 & - & 0.005 & 0.003 & - & 0.005 & 0.003 & - & 0.005 & 0.003 \\
\hline & & $(3.956)$ & $(2.144)$ & & $(3.950)$ & $(2.072)$ & & $(4.313)$ & $(2.424)$ & & $(3.896)$ & $(2.078)$ \\
\hline
\end{tabular}


Table 7: Information flow between the CDS, options, and equity markets around LBO announcements. This table reports OLS panel estimates and $t$-statistics (in parentheses) for the coefficients of the regression

$$
\operatorname{STKrtn}_{t}^{i}=a^{i}+\left[b_{t}^{i}+\sum_{z \in\{\mathrm{pre}, \mathrm{at}, \mathrm{post}\}} b^{z} D_{L}^{z, i}(t)\right] \operatorname{CDSinnov}_{e, o}^{i}(t-1)+\left[d_{t}^{i}+\sum_{z} d^{z} D_{L}^{z, i}(t)\right] \operatorname{IVinnov}_{e}^{i}(t-1)+\left[c_{t}^{i}+\sum_{z} c^{z} D_{L}^{z, i}(t)\right] \operatorname{STKrtn}_{t-1}^{i}+\epsilon_{t}^{i},
$$

where $b_{t}^{i}=b+b^{\mathrm{DD}}\left[D D_{t}^{i}-\operatorname{avg}_{j, s}\left(D D_{s}^{j}\right)\right]+b^{\mathrm{IV}}\left[\log \left(I V_{t}^{i}\right)-\operatorname{avg}_{j, s}\left(\log \left(I V_{s}^{j}\right)\right)\right]+b^{\mathrm{SZ}}\left[\log \left(S Z_{t}^{i}\right)-\operatorname{avg}_{j, s}\left(\log \left(S Z_{s}^{j}\right)\right)\right]+\sum_{\mathrm{sectors}} b^{s} D^{s, i}+\sum_{\mathrm{qtrs}} b^{q} D_{t}^{q, i}$, and $c_{t}^{i}$ and $d_{t}^{i}$ are defined in a similar fashion. Results are reported in columns seven through nine for three model specifications (I) $a^{i}=a, b_{t}^{i}=b, d_{t}^{i}=d$, and $c_{t}^{i}=c$, (II) $b^{s}=d^{s}=c^{s}=0$ and $b^{q}=d^{q}=c^{q}=0$, and (III) full model, where the latter uses the Basic Materials sector and the first quarter of 2002 as baseline. In columns one through three, we show the results for the information flow from the CDS market to the options market and in columns four through six the results for the information flow from the options market to the CDS market are reported. Note that the entries for $b$ and $d$ under columns marked III show the sample average of the quarterly dummy estimates and of their $t$-statistics.

\begin{tabular}{|c|c|c|c|c|c|c|c|c|c|}
\hline \multirow{2}{*}{$\begin{array}{l}\text { response } \\
\text { model spec. }\end{array}$} & \multicolumn{3}{|c|}{ IVrtn } & \multicolumn{3}{|c|}{ CDSrtn } & \multicolumn{3}{|c|}{ STKrtn } \\
\hline & I & II & III & I & II & III & I & II & III \\
\hline \multirow[t]{2}{*}{$b$} & 0.045 & 0.035 & 0.020 & 0.042 & 0.041 & 0.030 & -0.005 & -0.005 & -0.005 \\
\hline & (10.560) & $(7.557)$ & $(0.795)$ & $(20.659)$ & $(18.221)$ & (2.597) & $(-2.780)$ & $(-2.754)$ & $(-0.461)$ \\
\hline \multirow[t]{2}{*}{$b^{\text {pre }}$} & 1.202 & 1.191 & 1.164 & 0.302 & 0.291 & 0.320 & 0.100 & 0.101 & 0.100 \\
\hline & $(7.266)$ & (7.190) & $(7.001)$ & $(4.776)$ & (4.601) & (5.058) & (2.113) & $(2.136)$ & (2.119) \\
\hline \multirow[t]{2}{*}{$b^{\text {at }}$} & -3.553 & -3.569 & -3.562 & -0.017 & -0.065 & -0.041 & 0.040 & 0.043 & 0.038 \\
\hline & $(-14.844)$ & $(-14.893)$ & $(-14.831)$ & $(-0.103)$ & $(-0.385)$ & $(-0.243)$ & $(0.404)$ & $(0.435)$ & $(0.384)$ \\
\hline \multirow[t]{2}{*}{$b^{\text {post }}$} & -0.087 & -0.078 & -0.076 & -0.156 & -0.118 & -0.116 & 0.015 & 0.014 & 0.008 \\
\hline & $(-5.986)$ & $(-5.246)$ & $(-3.927)$ & $(-2.710)$ & $(-2.034)$ & $(-1.978)$ & (1.175) & $(1.062)$ & $(0.524)$ \\
\hline \multirow[t]{2}{*}{$b^{\mathrm{DD}}$} & - & -0.017 & -0.016 & - & 0.006 & 0.004 & - & 0.005 & 0.002 \\
\hline & & $(-4.086)$ & $(-3.573)$ & & (3.141) & $(2.162)$ & & (3.188) & (1.259) \\
\hline \multirow[t]{2}{*}{$b^{\mathrm{IV}}$} & - & 0.020 & 0.044 & - & 0.073 & 0.075 & - & -0.020 & -0.033 \\
\hline & & (1.819) & (3.036) & & (19.061) & (14.931) & & $(-4.372)$ & $(-5.390)$ \\
\hline$b^{\mathrm{SZ}}$ & - & $\begin{array}{r}0.004 \\
(1.016)\end{array}$ & $\begin{array}{r}0.007 \\
(1.674)\end{array}$ & - & $\begin{array}{r}-0.006 \\
(-2.771)\end{array}$ & $\begin{array}{r}-0.004 \\
(-1.748)\end{array}$ & - & $\begin{array}{r}-0.006 \\
(-3.606)\end{array}$ & $\begin{array}{r}-0.006 \\
(-3.363)\end{array}$ \\
\hline \multirow[t]{2}{*}{$d$} & & & & & & & -0.010 & -0.009 & -0.006 \\
\hline & & & & & & & $(-7.753)$ & $(-6.746)$ & $(-1.002)$ \\
\hline \multirow[t]{2}{*}{$d^{\text {pre }}$} & & & & & & & 0.023 & 0.026 & 0.018 \\
\hline & & & & & & & $(0.446)$ & $(0.498)$ & $(0.350)$ \\
\hline$d^{\text {at }}$ & & & & & & & 0.494 & 0.487 & 0.475 \\
\hline \multirow{2}{*}{$d^{\text {post }}$} & & & & & & & (3.464) & (3.405) & (3.325) \\
\hline & & & & & & & 0.002 & 0.002 & 0.003 \\
\hline \multirow[t]{2}{*}{$d^{\mathrm{DD}}$} & & & & & & & (0.0) & $\begin{array}{r}0.000 \\
0.000\end{array}$ & 0.000 \\
\hline & & & & & & & & $(0.208)$ & $(0.324)$ \\
\hline \multirow[t]{2}{*}{$d^{\mathrm{IV}}$} & & & & & & & - & -0.013 & -0.016 \\
\hline & & & & & & & & $(-5.626)$ & $(-5.534)$ \\
\hline$d^{\mathrm{SZ}}$ & & & & & & & - & 0.005 & 0.003 \\
\hline
\end{tabular}


Table 8: Model specifications for simulation study of information arrival and transition in CDS, options and equity markets. This table lists the specifications for the model structure in (16), (15) and (17) in terms of $\kappa^{c, E}, \kappa_{1}^{c, E}, \kappa_{2}^{c, E}$, $\kappa^{o, E}, \kappa_{1}^{o, E}$ and $\kappa_{2}^{o, E}$. A "x" under the first column means $\kappa^{c, E}=\Phi^{-1}(0.99) \sigma^{c}$, similarly for $\kappa_{1}^{c, E}$ and $\kappa_{2}^{c, E}$. A "x" under the fourth column means $\kappa^{o, E}=\Phi^{-1}(0.99) \sigma^{o}$, similarly for $\kappa_{1}^{o, E}$ and $\kappa_{2}^{o, E}$. $\kappa^{o, R}$ is set equal to $\Phi^{-1}(0.99) \sigma^{o}$. The remaining parameters were calibrated so as to mimic our tests in Sections 4 and 5 as closely as possible. In particular, we use all 150,000 (firm,date) pairs in our sample to estimate the model structure in (15) through (17), after removing all event dummies. This gives us the following parameter estimates: $\kappa^{c}=-0.0003, \kappa^{c, c}=0.0904$, $\kappa^{c, o}=0.0129, \kappa^{c, e}=-0.0934, \sigma^{c}=0.0310, \kappa^{o}=0.0009, \kappa^{o, c}=0.0153, \kappa^{o, o}=-0.1969, \kappa^{o, e}=-0.2075, \sigma^{o}=$ $0.0445, \kappa^{e}=0.0004, \kappa^{e, c}=-0.0029, \kappa^{e, o}=-0.0063, \kappa^{e, e}=-0.0156, \sigma^{e}=0.0195, \rho^{c, o}=0.0653, \rho^{c, e}=-0.0851$ and $\rho^{o, e}=-0.3027$. The return series are initialized at their sample average, that is, $\operatorname{CDSrtn}_{1}=-0.0004, \operatorname{IVrtn}_{1}=0.0006$ and $S T K r n_{1}=0.0003$. News and rumors arrive according to two independent Poisson processes with intensities $l^{E}$ and $l^{R}$, respectively. We set $l^{E}=0.01$ and $l^{R}=0.005$ to match the average frequency of upward jumps in CDS and in IV observed in the data, and use 150,000 days for the simulation. $\Phi$ denotes the standard normal distribution function.

\begin{tabular}{|c|c|c|c|c|c|c|}
\hline Model & $\kappa^{c, E}$ & $\kappa_{1}^{c, E}$ & $\kappa_{2}^{c, E}$ & $\kappa^{o, E}$ & $\kappa_{1}^{o, E}$ & $\kappa_{2}^{o, E}$ \\
\hline & \multicolumn{6}{|c|}{$\kappa^{e, E}=-\Phi^{-1}(0.99) \sigma^{e}$} \\
\hline M1 & $\mathrm{x}$ & - & - & $\mathrm{x}$ & - & - \\
\hline M2 & $\mathrm{x}$ & - & - & - & $\mathrm{x}$ & - \\
\hline M3 & $\mathrm{x}$ & - & - & - & - & $\mathrm{x}$ \\
\hline M4 & - & $\mathrm{x}$ & - & $\mathrm{x}$ & - & - \\
\hline M5 & - & $\mathrm{x}$ & - & - & $\mathrm{x}$ & - \\
\hline M6 & - & $\mathrm{x}$ & - & - & - & $\mathrm{x}$ \\
\hline M7 & - & - & $\mathrm{x}$ & $\mathrm{x}$ & - & - \\
\hline M8 & - & - & $\mathrm{x}$ & - & $\mathrm{x}$ & - \\
\hline M9 & - & - & $\mathrm{x}$ & - & - & $\mathrm{x}$ \\
\hline M10 & $1 / 4 \mathrm{x}$ & $3 / 4 \mathrm{x}$ & - & - & $1 / 4 \mathrm{x}$ & $3 / 4 \times$ \\
\hline \multirow[t]{2}{*}{ M11 } & - & $3 / 4 \mathrm{x}$ & $1 / 4 \mathrm{x}$ & $7 / 8 x$ & - & $1 / 8 x$ \\
\hline & \multicolumn{6}{|c|}{$\kappa^{e, E}=\Phi^{-1}(0.99) \sigma^{e}$} \\
\hline M12 & - & $1 / 4 \mathrm{x}$ & $3 / 4 x$ & - & $3 / 4 x$ & $1 / 4 \mathrm{x}$ \\
\hline
\end{tabular}


Table 9: Simulation study of information arrival and transition in CDS, options and equity markets. We simulate from the framework in (16), (15) and (17), using the model specifications described in Table 8. Based on the simulated return series, we compute CDS and IV innovations as defined in Section 2.2.1, but with only one lag and by ignoring the interaction with $D D_{t}$. This table reports OLS panel estimates and $t$-statistics (in parentheses) for the coefficients of three sets of regressions: (6), specification I of (11), and specification I of (13). Our focus is on the information flow from CDS and options markets prior to negative credit news, so we replace $\sum_{z \in\{\text { pre,at,post }\}} b^{z} D_{\bullet}^{z, i}(t)$ by $b^{\text {pre }} D_{t+1}^{E}+b^{a t} D_{t}^{E}$. Similarly for $\sum_{z \in\{\text { pre,at,post }\}} c^{z} D_{\bullet}^{z, i}(t)$ and $\sum_{z \in\{\text { pre,at,post }\}} d^{z} D_{\bullet}^{z, i}(t)$.

\begin{tabular}{|c|c|c|c|c|c|c|c|c|c|c|c|c|}
\hline model spec. & M1 & M2 & M3 & M4 & M5 & M6 & M7 & M8 & M9 & M10 & M11 & M12 \\
\hline & \multicolumn{12}{|c|}{ Information flow from the CDS market to the options market } \\
\hline \multirow[t]{2}{*}{$b$} & 0.027 & 0.029 & 0.030 & 0.024 & 0.024 & 0.024 & 0.024 & 0.024 & 0.024 & 0.025 & 0.024 & 0.024 \\
\hline & $(6.951)$ & $(7.613)$ & $(7.784)$ & $(6.217)$ & $(6.033)$ & $(6.125)$ & $(6.062)$ & $(6.245)$ & $(6.174)$ & $(6.558)$ & $(6.334)$ & (6.331) \\
\hline \multirow[t]{4}{*}{$b^{p r e}$} & -0.013 & -0.027 & -0.024 & -0.004 & -0.017 & -0.016 & -0.014 & 1.206 & -0.016 & -0.034 & -0.028 & 0.992 \\
\hline & $(-0.349)$ & $(-0.700)$ & $(-0.613)$ & $(-0.111)$ & $(-0.436)$ & $(-0.420)$ & $(-0.888)$ & $(76.674)$ & $(-0.560)$ & $(-0.892)$ & $(-0.828)$ & $(45.461)$ \\
\hline & -0.114 & -0.071 & -0.060 & 1.186 & -0.064 & -0.023 & -0.130 & -0.060 & -0.054 & -0.046 & 1.258 & -0.100 \\
\hline & $(-3.032)$ & $(-1.906)$ & $(-1.604)$ & $(75.330)$ & $(-2.177)$ & $(-1.302)$ & $(-3.436)$ & $(-1.644)$ & $(-1.421)$ & $(-2.143)$ & (63.933) & $(-2.713)$ \\
\hline \multirow{7}{*}{ or } & \multicolumn{12}{|c|}{ Information flow from the options market to the CDS market } \\
\hline & 0.026 & 0.026 & 0.026 & 0.027 & 0.026 & 0.026 & 0.024 & 0.026 & 0.026 & 0.026 & 0.025 & 0.026 \\
\hline & $(14.620)$ & $(14.205)$ & $(13.924)$ & $(14.762)$ & $(13.955)$ & $(14.257)$ & $(13.561)$ & $(13.919)$ & $(13.898)$ & $(14.286)$ & $(13.901)$ & $(14.198)$ \\
\hline & -0.003 & 0.013 & -0.014 & -0.019 & -0.015 & 0.572 & -0.002 & 0.001 & -0.006 & 0.504 & 0.199 & 0.042 \\
\hline & $(-0.146)$ & $(0.774)$ & $(-1.795)$ & $(-1.079)$ & $(-0.854)$ & $(76.549)$ & $(-0.107)$ & $(0.040)$ & $(-0.465)$ & $(54.434)$ & (11.728) & $(2.443)$ \\
\hline & -0.009 & 0.576 & -0.100 & 0.004 & -0.008 & 0.026 & 0.002 & 0.025 & 0.007 & 0.042 & 0.009 & -0.037 \\
\hline & $(-0.504)$ & $(77.213)$ & $(-5.738)$ & $(0.248)$ & $(-0.540)$ & $(1.508)$ & $(0.126)$ & (3.043) & $(0.391)$ & $(2.443)$ & $(0.551)$ & $(-3.313)$ \\
\hline & \multicolumn{12}{|c|}{ Information flow from CDS and options markets to the equity market } \\
\hline \multirow[t]{2}{*}{$b$} & -0.002 & -0.002 & -0.002 & -0.003 & -0.002 & -0.003 & -0.003 & -0.003 & -0.003 & -0.002 & -0.003 & -0.002 \\
\hline & $(-0.973)$ & $(-1.039)$ & $(-0.971)$ & $(-1.526)$ & $(-1.477)$ & $(-1.565)$ & $(-1.653)$ & $(-1.627)$ & $(-1.578)$ & $(-1.444)$ & $(-1.558)$ & $(-1.187)$ \\
\hline \multirow[t]{2}{*}{$b^{\text {pre }}$} & 0.025 & 0.022 & 0.024 & 0.028 & 0.026 & 0.024 & -0.520 & -0.520 & -0.259 & 0.029 & -0.114 & 0.455 \\
\hline & (1.481) & $(1.364)$ & (1.423) & $(1.701)$ & $(1.597)$ & $(1.478)$ & $(-76.346)$ & $(-76.352)$ & $(-20.979)$ & $(1.764)$ & $(-7.932)$ & $(48.626)$ \\
\hline \multirow[t]{2}{*}{$b^{a t}$} & 0.040 & 0.072 & 0.013 & -0.524 & -0.273 & -0.541 & 0.055 & 0.053 & 0.044 & -0.586 & 0.005 & 0.022 \\
\hline & $(2.417)$ & $(4.503)$ & $(0.824)$ & $(-77.013)$ & $(-21.598)$ & $(-76.181)$ & $(3.452)$ & (3.323) & $(2.731)$ & $(-60.807)$ & $(0.494)$ & (1.374) \\
\hline \multirow[t]{2}{*}{$d$} & -0.007 & -0.007 & -0.007 & -0.007 & -0.007 & -0.007 & -0.006 & -0.007 & -0.007 & -0.007 & -0.006 & -0.007 \\
\hline & $(-5.547)$ & $(-6.063)$ & $(-5.951)$ & $(-5.568)$ & $(-6.147)$ & $(-6.050)$ & $(-5.468)$ & $(-5.998)$ & $(-6.062)$ & $(-6.116)$ & $(-5.565)$ & $(-5.651)$ \\
\hline \multirow[t]{2}{*}{$d^{p r e}$} & -0.013 & -0.016 & 0.006 & -0.017 & -0.015 & 0.005 & -0.018 & -0.013 & -0.232 & 0.006 & -0.068 & 0.077 \\
\hline & $(-1.127)$ & $(-1.430)$ & (1.168) & $(-1.484)$ & $(-1.360)$ & $(1.094)$ & $(-1.628)$ & $(-1.152)$ & $(-29.241)$ & (1.038) & $(-6.219)$ & $(7.057)$ \\
\hline \multirow[t]{2}{*}{$d^{a t}$} & 0.017 & -0.359 & 0.025 & 0.032 & -0.221 & 0.029 & -0.020 & -0.016 & 0.017 & -0.118 & -0.011 & 0.079 \\
\hline & (1.473) & $(-75.660)$ & $(2.224)$ & $(2.828)$ & $(-27.214)$ & $(2.616)$ & $(-1.878)$ & $(-1.746)$ & $(1.573)$ & $(-10.749)$ & $(-0.965)$ & (10.001) \\
\hline
\end{tabular}




\section{Figures}
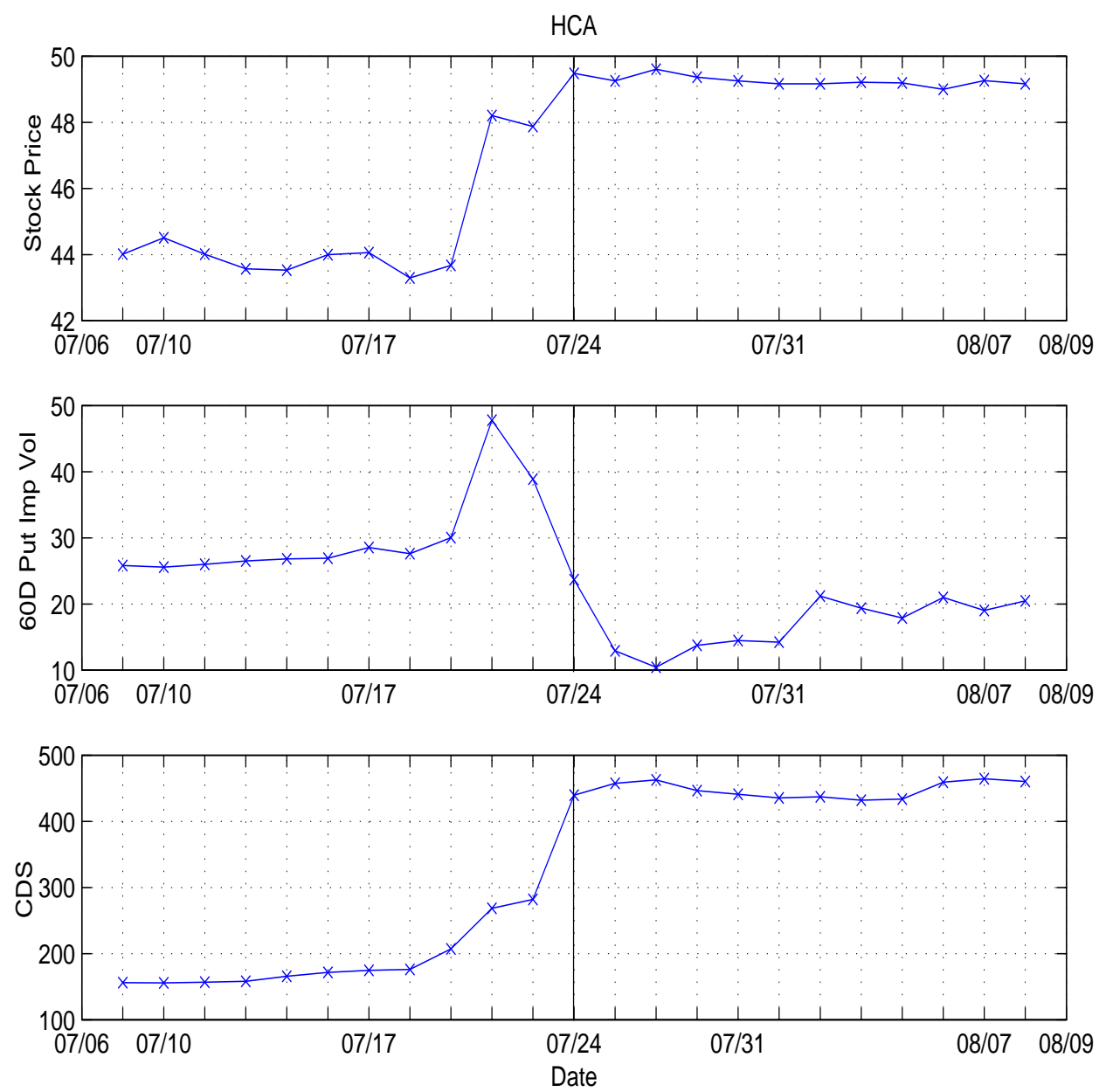

Figure 1: Returns on CDS, options, and stock on HCA around the July 24, 2006 LBO announcement. Source: Markit, OptionMetrics, and CRSP. 

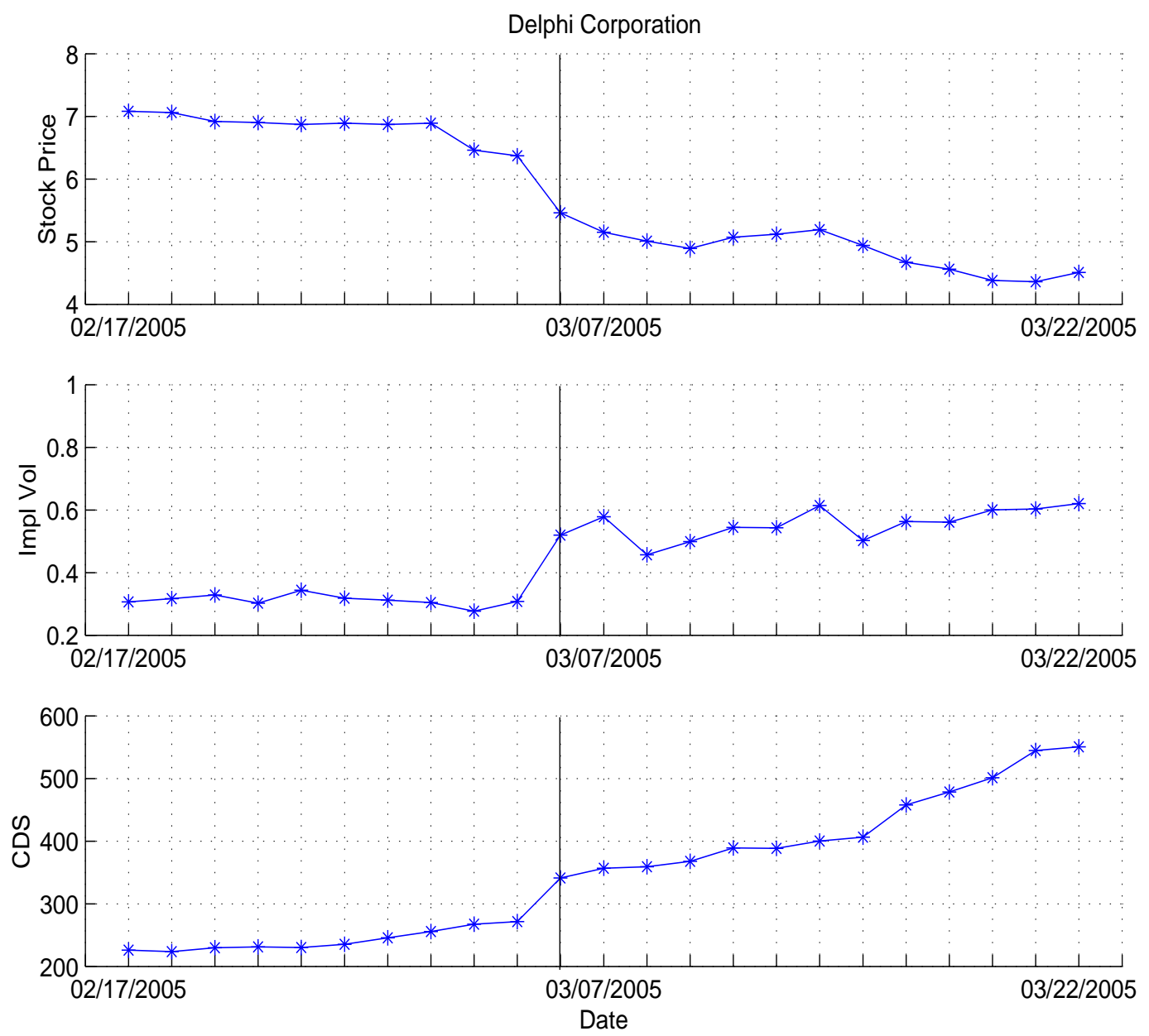

Figure 2: Returns on CDS, options, and stock on Delphi around the March 7, 2005 announcement of further accounting problems. Source: Markit, OptionMetrics, and CRSP. 

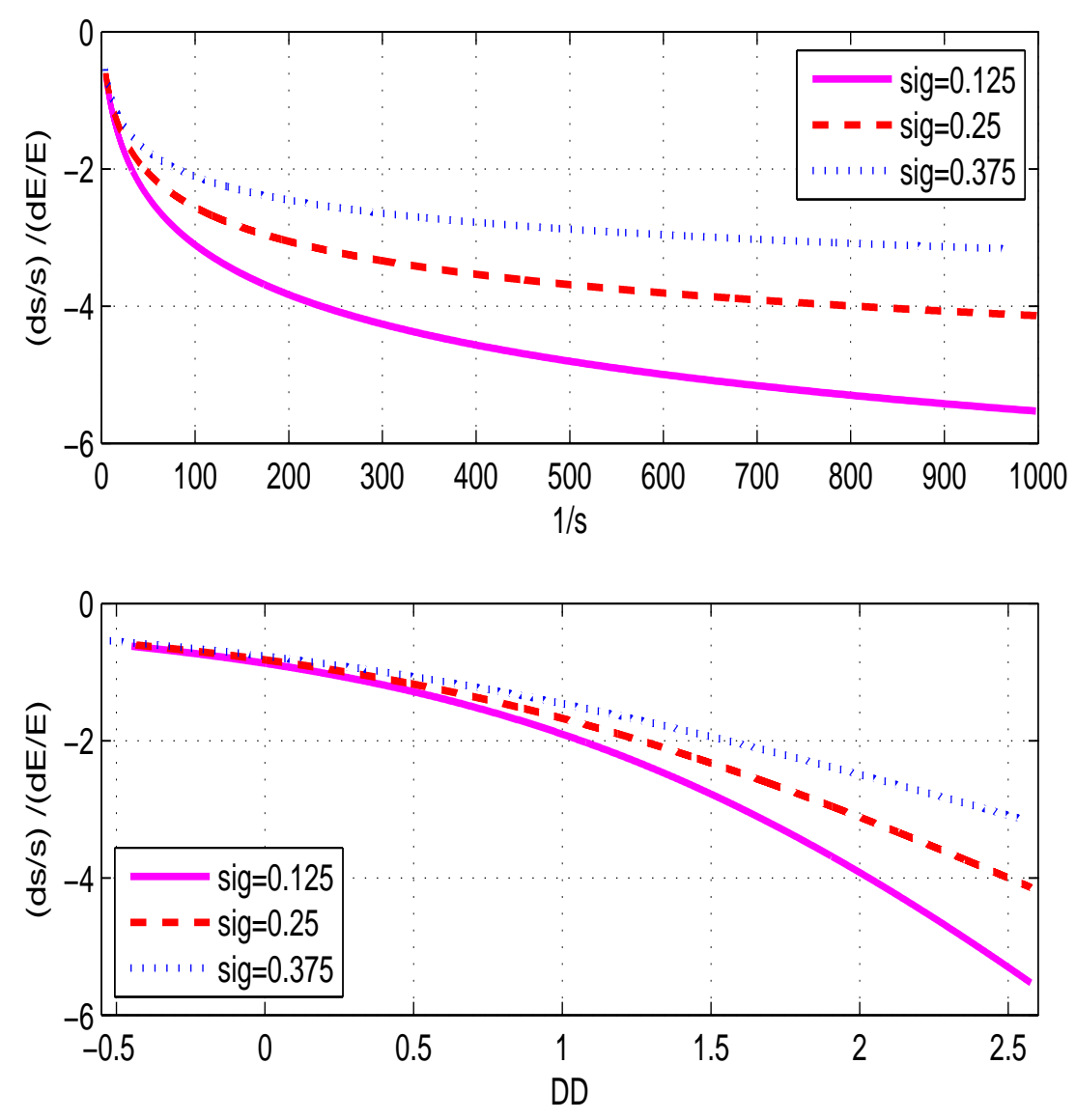

Figure 3: The figure shows the elasticity of credit spreads $s$ with respect to the value of equity $E$, defined by $(d s / s) /(d E / E)$ computed under the Black-Scholes-Merton framework of corporate default. Assuming an asset volatility of sig, we price a zero-coupon bond with face value of 100 that matures five years from now. The risk-free interest rate is set equal to $4 \%$. The top panel plots the credit spread elasticity over the inverse of the level of credit spreads. The bottom panel displays the credit spread elasticity as a function of the firm's risk-neutral distance to default. 

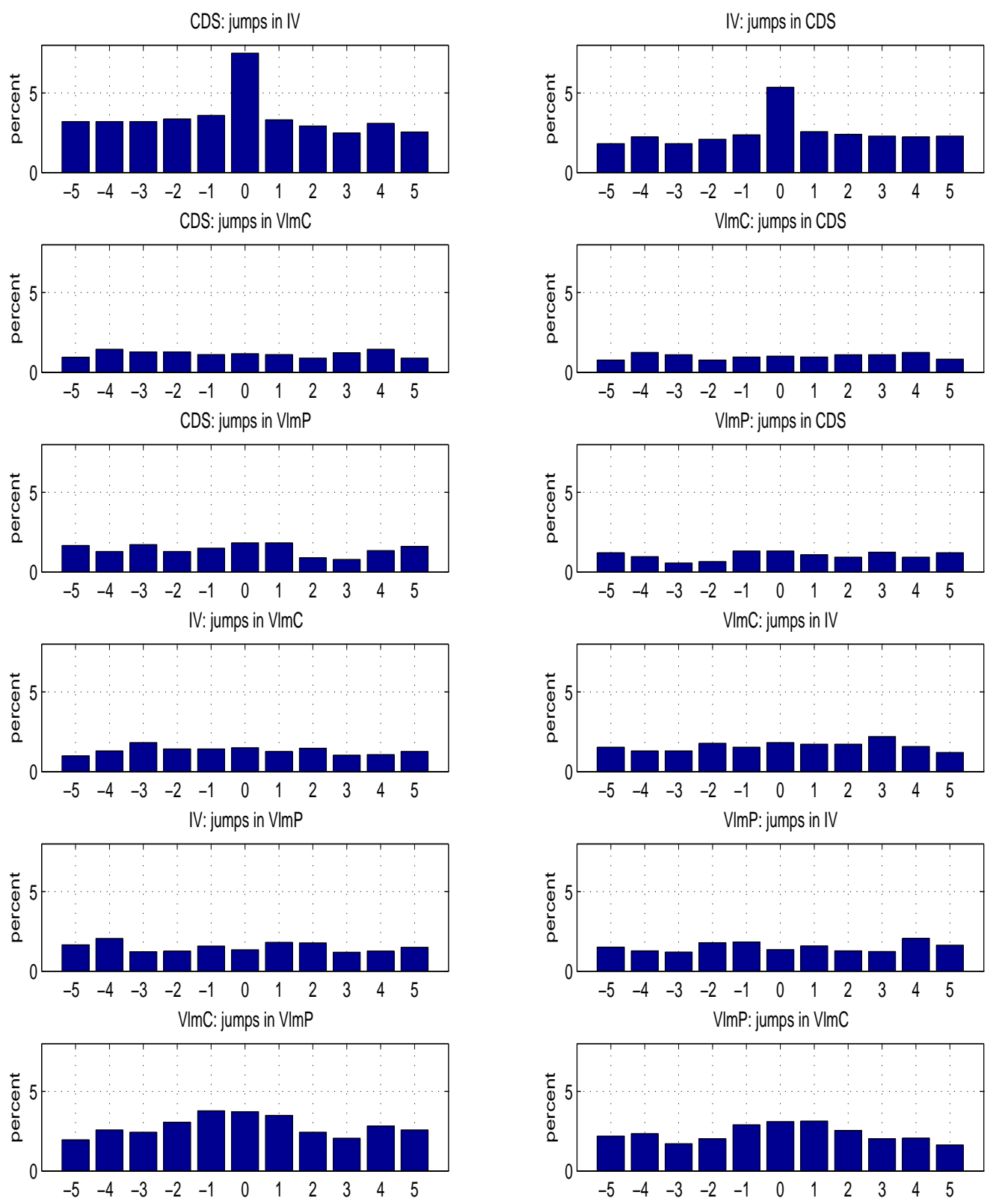

Figure 4: The first graph in the top panel shows the distribution, across firms and time, of upward jumps in IV (as defined in (4)) for five days before until five days after an upward jump in CDS rates (as defined in (3)). The second graph in the top panel shows the distribution of upward jumps in CDS rates for five days before until five days after an upward jump in IV. Similarly for all other subplots. 

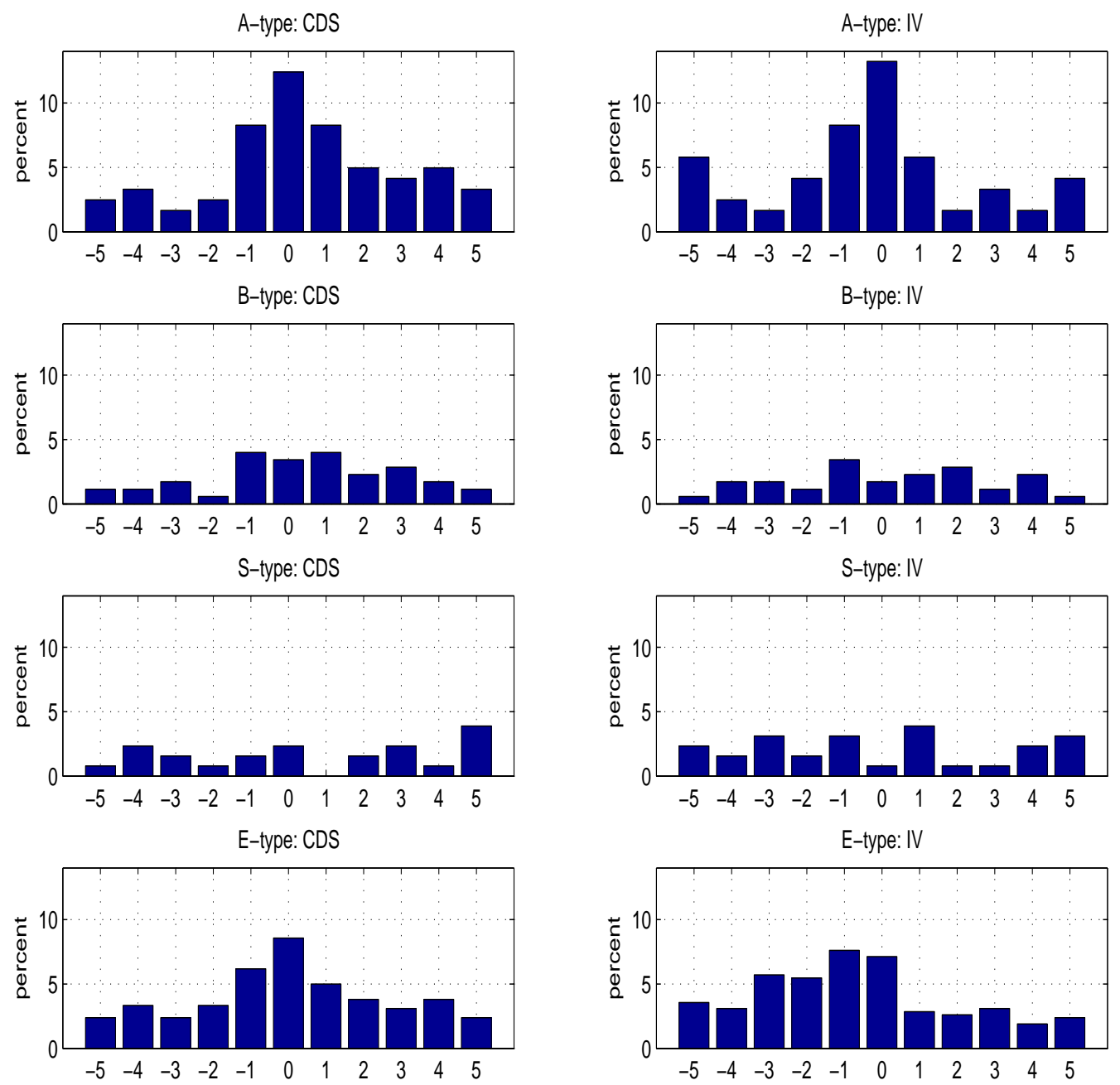

Figure 5: Distribution, across firms and time, of upward jumps in CDS rates (as defined in (3)) and in IV (as defined in (4)) for five days before until five days after the announcement, for each type of announcement. 

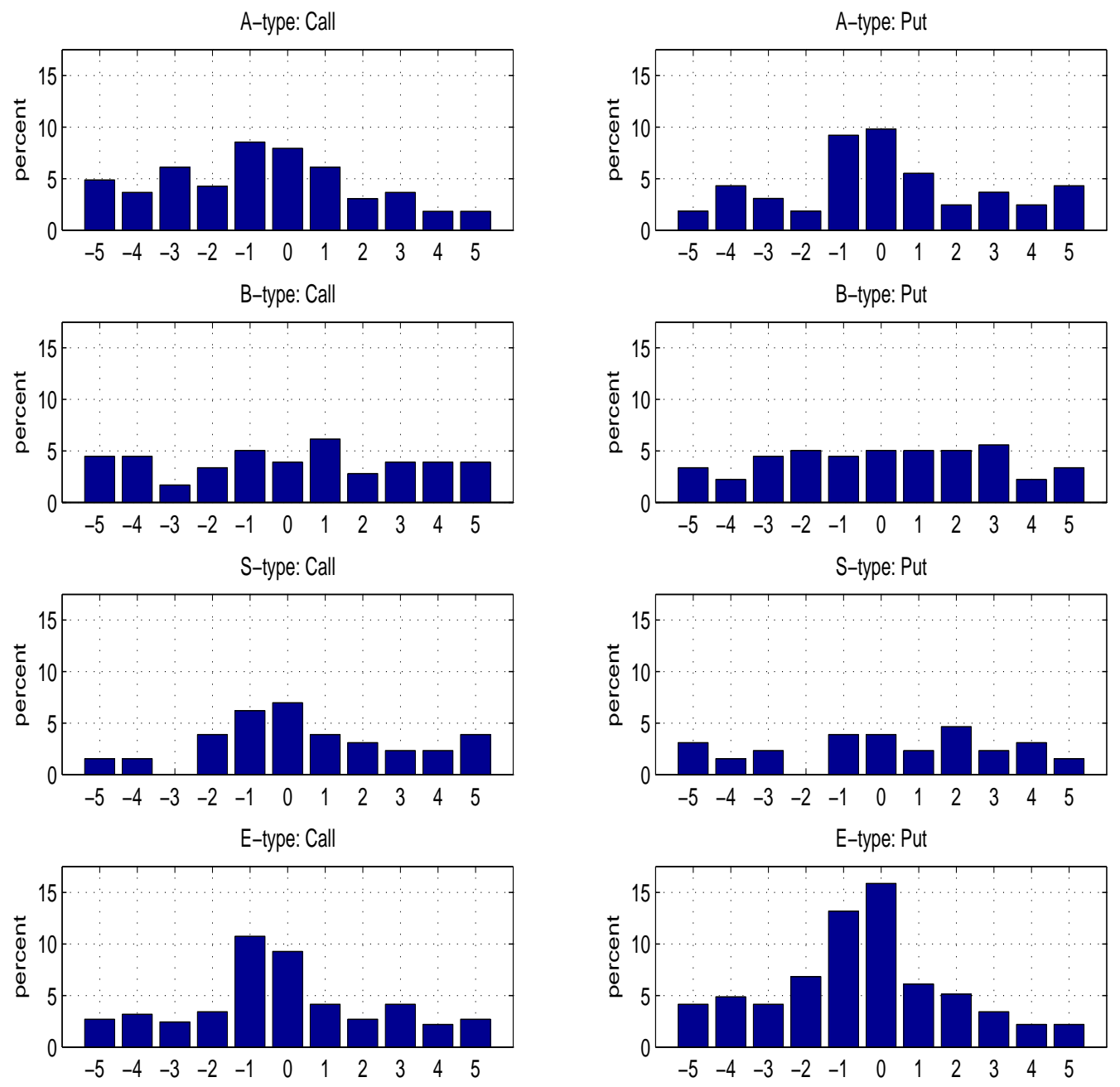

Figure 6: Distribution, across firms and time, of upward jumps in call-option volume and in put-option volume (as defined in (5)) for five days before until five days after the announcement, for each type of announcement. 


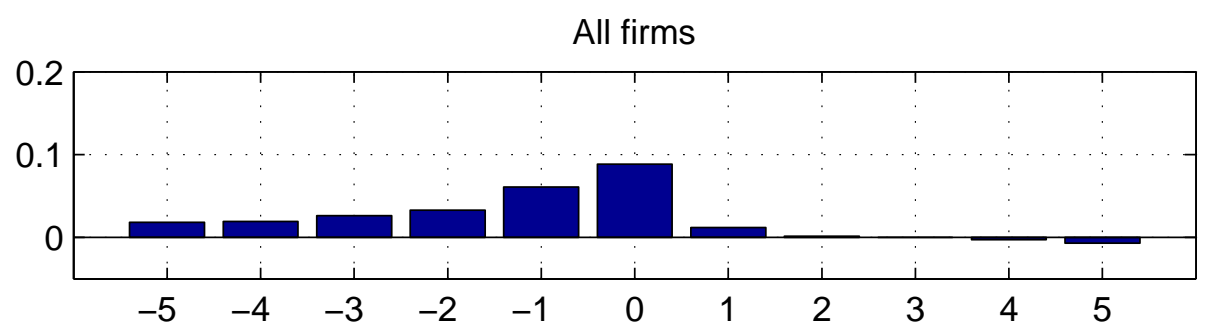

Firms with Type A announcements

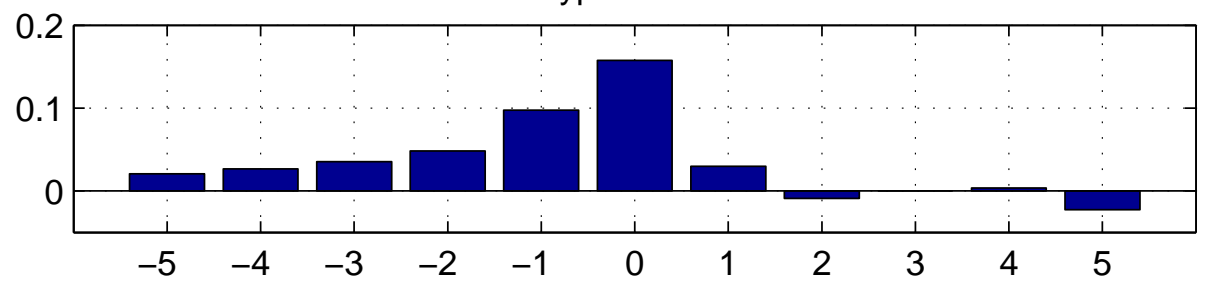

Firms with Type $L$ announcements

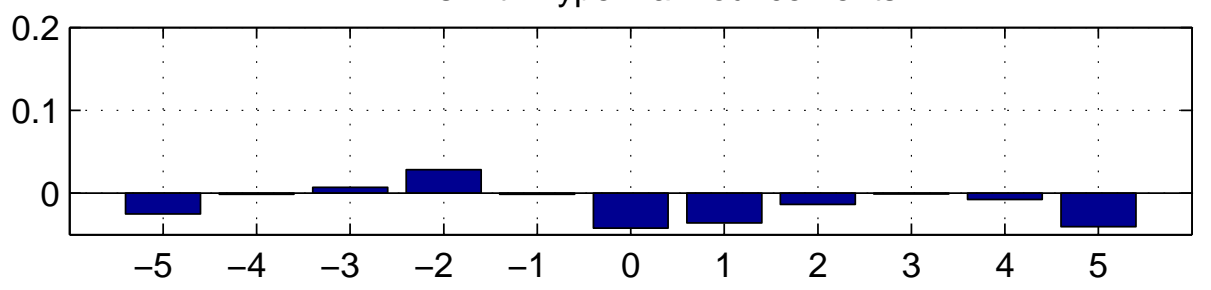

Figure 7: Cross-correlation between percentage changes in CDS rates at time $t$ and percentage changes in implied volatilities at time $t+k$, for $k=-5, \ldots, 5$, as a function of $k$. The top panel uses all firms in our sample. The middle (bottom) panel uses firms for which at least one Type A (Type L) announcement was made during the sample period. In each panel, the cross-correlations for individual firms are averaged across firms. 


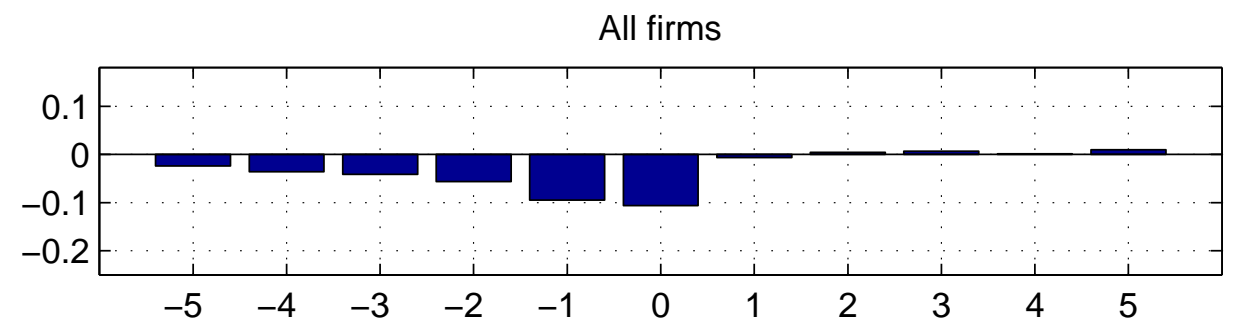

Firms with Type $A$ announcements

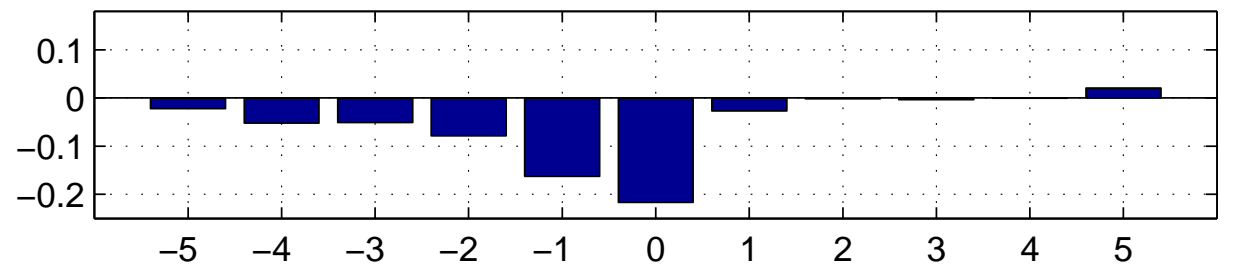

Firms with Type $L$ announcements

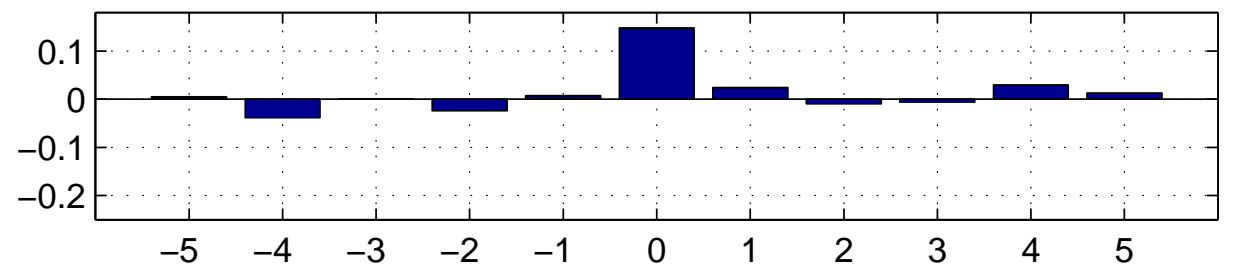

Figure 8: Cross-correlation between percentage changes in CDS rates at time $t$ and stock returns at time $t+k$, for $k=-5, \ldots, 5$, as a function of $k$. The top panel uses all firms in our sample. The middle (bottom) panel uses firms for which at least one Type A (Type L) announcement was made during the sample period. In each panel, the cross-correlations for individual firms are averaged across firms. 


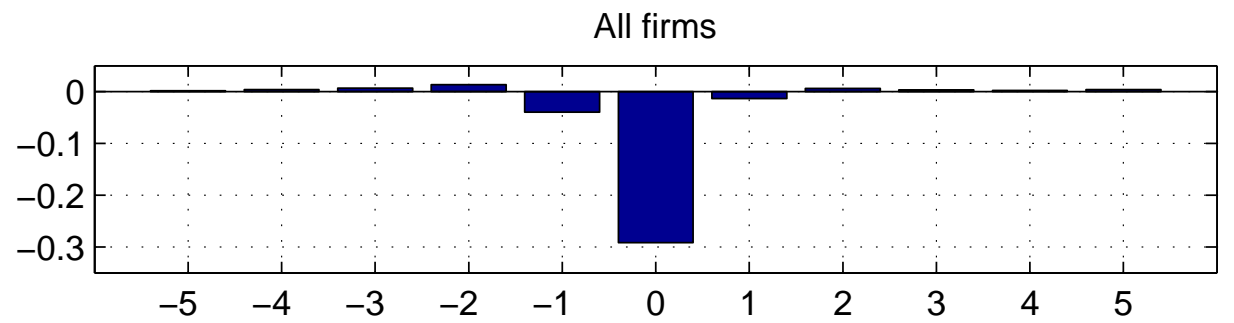

Firms with Type $A$ announcements

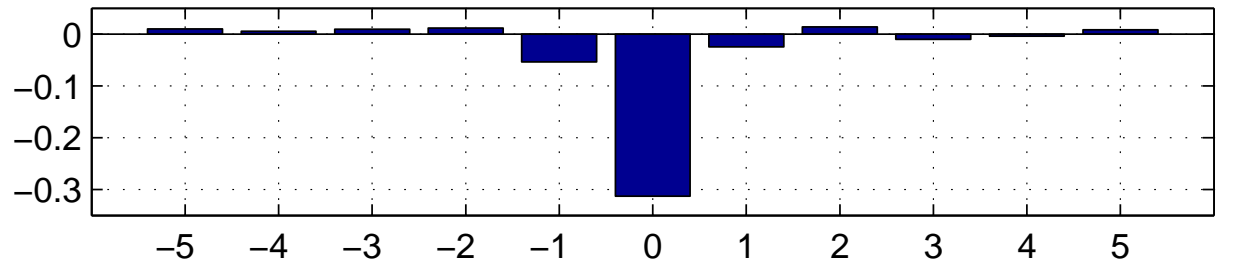

Firms with Type $L$ announcements

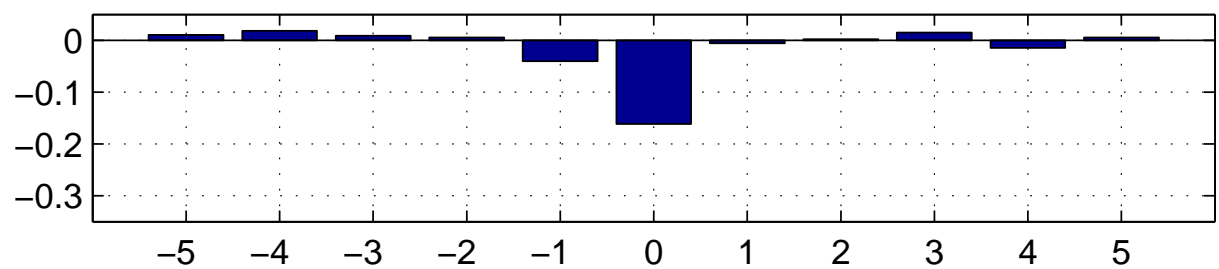

Figure 9: Cross-correlation between percentage changes in implied volatilities at time $t$ and stock returns at time $t+k$, for $k=-5, \ldots, 5$, as a function of $k$. The top panel uses all firms in our sample. The middle (bottom) panel uses firms for which at least one Type A (Type L) announcement was made during the sample period. In each panel, the cross-correlations for individual firms are averaged across firms. 

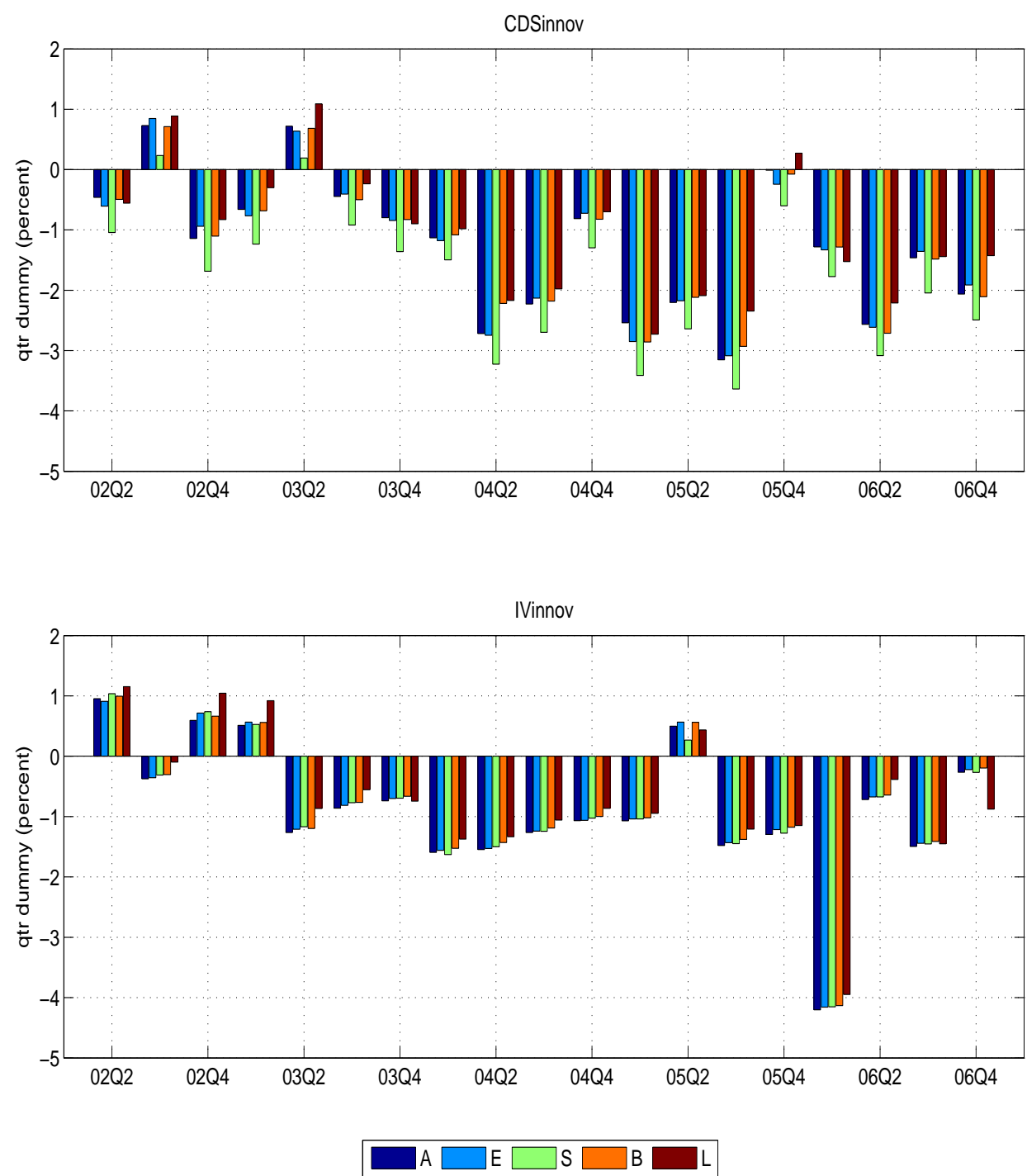

Figure 10: Quarterly dummy multipliers for innovations in CDS rates (top panel) and IV (bottom panel), as estimated for model specification III of (14), with $\bullet \in\{\mathrm{A}, \mathrm{E}, \mathrm{S}, \mathrm{B}, \mathrm{L}\}$. 


\section{References}

Acharya, V., T. Johnson, 2007a. Insider Trading in Credit Derivatives. Journal of Financial Economics 84, 110-141.

— , 2007b. More Insiders, More Insider Trading: Evidence from Private Equity Buyouts. Workin paper, London Business School, London.

Berman, D. K., S. Ng, 2006. Trading in Harrah's Contracts Surges Before LBO Disclosure. Wall Street Journal October 4, C3.

Black, F., M. Scholes, 1973. The Pricing of Options and Corporate Liabilities. Journal of Political Economy 81, 637-654.

Blanco, R., S. Brennan, I. Marsh, 2005. An Empirical Analysis of the Dynamic Relationship between Investment Grade Bonds and Credit Default Swaps. Journal of Finance 60, 2255-2281.

Buraschi, A., F. Trojani, A. Vedolin, 2007. The Joint Behavior of Credit Spreads, Stock Options and Equity Returns when Investors Disagree. Workin paper, Imperial College, London.

Cao, C., Z. Chen, J. M. Griffin, 2005. Informational Content of Option Volume Prior to Takeovers. Journal of Business 78, 1073-1109.

Cao, C., F. Yu, Z. Zhong, 2007. The Information Content of Option-Implied Volatility for Credit Default Swap Valuation. Working paper, Penn State University.

Chakravarty, S., H. Gulen, S. Mayhew, 2004. Informed Trading in Stock and Option Markets. Journal of Finance 59, 1235-1257.

Cremers, M., J. Driessen, P. Maenhout, D. Weinbaum, 2005. Individual Stock Option Prices and Credit Spreads. Working paper, Yale School of Management.

Duffie, D., L. Saita, K. Wang, 2007. Multiperiod Corporate Default Probabilities with Stochastic Covariates. Journal of Financial Economics 83, 635-665.

Duffie, D., K. J. Singleton, 2003. Credit Risk: Pricing, Measurement, and Management. Princeton University Press, Princeton, New Jersey. 
Easley, D., M. O'Hara, P. S. Srinivas, 1998. Option Volume and Stock Prices: Evidence on Where Informed Traders Trade. Journal of Finance 53, 431-465.

Hilscher, J., 2007. Is the Corporate Bond Market Forward Looking?. Working paper, Brandeis University.

International Swaps and Derivatives Association, 2007. ISDA Market Survey historical data. Available from http://isda.org/statistics/historical.html.

Lakonishok, J., I. Lee, N. D. Pearson, A. M. Poteshman, 2007. Option Market Activity. Review of Financial Studies 20, 813-857.

Longstaff, F., S. Mithal, E. Neis, 2005. Corporate Yield Spreads: Default Risk or Liquidity? New Evidence from the Default Swap Market. Journal of Finance 60, 2213-2253.

Mengle, D., 2007. Credit Derivatives: An Overview. Federal Reserve Bank of Atlanta Economic Review 97, 1-24.

Merton, R. C., 1974. On the Pricing of Corporate Debt: The Risk Structure of Interest Rates. Journal of Finance 29, 449-470.

Norden, L., M. Weber, 2004. Informational Efficiency of Credit Default Swap and Stock Markets: The Impact of Credit Rating Announcements. Journal of Banking \& Finance 28, 2813-43.

— 2007. The Comovement of Credit Default Swap, Bond and Stock Markets: An Empirical Analysis. Working paper, University of Mannheim, Germany.

Pan, J., A. M. Poteshman, 2006. The Information in Option Volume for Future Stock Prices. Review of Financial Studies 19, 871-908.

Scannell, K., S. Ng, 2006. Can Anyone Police the Swaps?. Wall Street Journal August 31, C1.

Zhang, B. Y., H. Zhu, H. Zhu, 2005. Explaining Credit Default Swap Spreads with the Equity Volatility and Jump Risks of Individual Firms. Working paper. Federal Reserve Board. 